\title{
Historia
}

\section{Indización y estudio de la Gaceta Médico- Quirúrgica Jerezana (1871-1872)}

Index and study of the Jerezana Medical-Surgical Gazette (1871-1872)

Índice e estudo da Gazette Médico-Cirúrgica Jerezana (1871-1872)

\author{
Francisco Herrera-Rodríguez ${ }^{1}$ \\ ${ }^{1}$ Catedrático E.U. (jubilado) (Historia de la Enfermería y Fundamentos e \\ Historia de la Fisioterapia. Facultad de Enfermería y Fisioterapia. Universidad \\ de Cádiz). \\ Cómo citar este artículo en edición digital: Herrera-Rodriguez, F. (2019). Indización y estudio de la \\ "Gaceta Médico-Quirúrgica Jerezana" (1871-1872). Cultura de los Cuidados (Edición digital), 23 \\ (54). Recuperado de http://dx.doi.org/10.14198/cuid.2019.54.11 \\ Correspondencia: Santo Domingo de la Calzada, n.ำ11-3.․ A 11012-Cádiz \\ Correo electrónico de contacto: fraherod57@gmail.com \\ Recibido: 03/11/2018; Aceptado: 21/03/2019
}

\section{ABSTRACT}

In this article are studied 12 issues of the Jerezana Medical-Surgical Gazette, corresponding to the years 1871 and 1872, published in Jerez de la Frontera (Cádiz) by its founder and director "Francisco Revueltas Carrillo Montel" (1839-1887). In this journal are offered clinical histories of the Departments of Surgery and Medicine of the Hospital of Santa Isabel de Jerez, as well as others of the private clinical experiences by some authors, as the surgeon, from El Puerto de Santa María (Cádiz), Federico Rubio y Galí (1827-1902). It is also appreciated in the journal the practical teaching work carried out in those years, in the above mentioned hospital, to some students from the Cádiz Faculty of Medicine who also published their clinical experiences in the Gazette; and we have also known that "practicante" an midwives were trained in this hospital. The magazine offers statistical information about the hospital, the hospice, the home of foundlings and the sanitary status of the city. In our work we carry out a chronological index of the 12 issues of the journal, which includes the authors, articles and news published.

Keywords: Medical Press, Jerezana MedicalSurgical Gazette, "Francisco Revueltas Carrillo Montel", Federico Rubio y Galí, 19th Century, Democratic Six Years Period, Hospital of Santa Isabel (Jerez), Jerez de la Frontera, Spain. 


\section{RESUMO}

Neste trabalho estudamos 12 edições da do Médico-Cirúrgica Diário Jerezana, para os anos 1871 e 1872, publicadas em Jerez de la Frontera por seu fundador e diretor "Francisco Revueltas Carrillo Montel" (1839-1887). Nesta revista prontuários dos Departamentos de Cirurgia e Medicina Hospital de Santa Isabel de Jerez, bem como a experiência clínica privada de alguns autores, entre os quais o cirurgião El Puerto de Santa María Federico Rubio e Gali oferta (1827-1902). Destacando trabalho prático, realizado naqueles anos no hospital referido alguns alunos da Faculdade de Medicina de Cadiz também publicou as suas experiências clínicas no Diário visto na revista; embora também saibamos que os "practicante" e parteiras foram treinados neste hospital. A revista oferece informações estatísticas sobre o hospital, o hospício, a casas de crianças enjeitadas e o status sanitário da cidade. Em nosso trabalho, realizamos um índice cronológico das 12 edições da revista, que inclui os autores, artigos e notícias publicadas.

Palavras chave: Revista Médica, MédicoCirúrgica Diário Jerezana, "Francisco Revueltas Carrillo Montel", Federico Rubio y Galí, do século XIX, Período Seis Años Democrático, Hospital de Santa Isabel (Jerez), Jerez de la Frontera, na Espanha.

\section{RESUMEN}

En este artículo se estudian 12 números de la Gaceta Médico-Quirúrgica Jerezana, correspondientes a los años 1871 y 1872, publicada en Jerez de la Frontera por su fundador y director "Francisco Revueltas Carrillo Montel" (1839-1887). En esta revista se ofrecen historias clínicas de los Departamentos de Cirugía y Medicina del Hospital de Santa Isabel de Jerez, así como de la experiencia clínica privada de algunos autores, entre los que destaca el cirujano de El Puerto de Santa María Federico Rubio y Galí (1827-1902). Se aprecia en la revista la labor docente de carácter práctico realizada en esos años en el referido hospital, con algunos alumnos de la Facultad de Medicina de Cádiz, que publicaron sus experiencias clínicas en la Gaceta; aunque también sabemos que se formaron practicante $y$ matronas en este hospital. La revista ofrece información estadística sobre el hospital, el hospicio, la casa de expósitos y el estado sanitario de la ciudad. Realizamos en nuestro trabajo un índice cronológico de los 12 números de la revista en el que se incluyen a los autores, los artículos y noticias publicadas.

Palabras clave: Prensa médica, Gaceta Médico-Quirúrgica Jerezana, "Francisco Revueltas Carrillo Montel", Federico Rubio y Galí, Siglo XIX, Sexenio democrático, Hospital de Santa Isabel (Jerez), Jerez de la Frontera, España.

\begin{abstract}
A Cristóbal Orellana González que durante más de dos décadas ha guiado mis pasos en el Archivo Municipal de Jerez de la Frontera.
\end{abstract}

La historiografía sobre la prensa médica en la España de los siglos XIX y XX se ha incrementado de manera muy notable en las últimas décadas, tanto que sería imposible en las páginas de este artículo reflejar la citada producción de forma pormenorizada; sin embargo, si es necesario en el marco general de esta introducción dejar constancia de los autores más notables que han realizado catálogos recopilatorios de las citadas revistas o incluso estudios bibliométricos. Cabe recordar en la primera de las facetas apuntadas a dos autores: 
Méndez Álvaro y Larra Cerezo. Francisco Méndez Álvaro, editó sus "Breves apuntes para la Historia del periodismo médico en España" en El Siglo Médico, en 1882, y posteriormente como folleto en 1883; casi un siglo más tarde fue editada esta obra con introducción, edición e índices del profesor Riera Palmero (Méndez Álvaro, 1978; RieraPalmero, 1978). En esta línea está también Ángel de Larra y Cerezo que, en 1905, publicó su Historia resumida del periodismo médico en España. Más cercanos en el tiempo se deben apuntar los trabajos fundamentales de López Piñero y Terrada tanto en lo que se refiere a catalogación como impulsando los estudios bibliométricos (1980, 1900 y 1991).

La constitución del moderno periodismo médico en España se produjo durante el período que abarca el reinado de Isabel; López Piñero considera que este periodo histórico constituye una "etapa intermedia", entre el colapso de la actividad médicocientífica que se produce durante la guerra de la Independencia, el reinado de Fernando VII y la etapa de recuperación del último cuarto del siglo XIX. Hay que tener en cuenta que entre 1809 y 1833 este autor señala que se fundaron en España 5 revistas médicas, mientras que entre 1834 y 1868 fueron 128, y entre 1869 y 1900 un total de 265. Tiene que ver este hecho con la desaparición de la rígida censura que el absolutismo había impuesto, circunstancia que motivó este crecimiento en el número de publicaciones de revistas y también de libros médicos (López Piñero, 1992). De las numerosas revistas que aparecieron en los años centrales del siglo XIX se pueden destacar, El Siglo Médico, La España Médica, El Compilador Médico, etc. Durante la "etapa intermedia" se asimiló plenamente en España la medicina anatomoclínica y algunos aspectos de la nueva medicina de laboratorio. En el último tercio del siglo XIX debe destacarse que la "revolución democrática" de 1868 permitió que la actividad científica española se desarrollara en completa libertad desde el punto de vista ideológico, y que en estas décadas del siglo se introdujera en España la mentalidad fisiopatológica y la progresiva aparición de las especialidades en algunos centros de formación de nuestro país (López-Piñero, 1992).

En lo referido al estudio de la prensa médica en el Cádiz del siglo XIX hay que destacar los trabajos pioneros de Orozco sobre el Periódico de la Sociedad Médico Quirúrgica de Cádiz, que López Piñero ha señalado como la revista médica de mayor altura de la España fernandina (OrozcoAcuaviva, 1980a, 1980b; López Piñero, 1992). El propio Orozco también centró su atención en revistas como los Archivos Homeopáticos, La Crónica de los Hospitales, La Crónica Oftalmológica, la Gaceta de Higiene y Climatología, la Crónica de especialidades médico-quirúrgicas, etc. (Orozco-Acuaviva, 1980a, 1981a, 1981b, 1987). Otros miembros de su escuela, y otros autores, han seguido profundizando tanto en la indización como en el estudio de los contenidos de la prensa médica gaditana (Maraver-Eyzaguirre, 1982; Doña-Nieves, 1987b，1987c，1998; Márquez-Espinós, 1984, 1987; LasarteCalderay, 1995; Lasarte-Calderay y HerreraRodríguez, 1992; Ramos-Contreras, 1994; Herrera-Rodríguez y Lasarte-Calderay, 1996; Camacho-Iglesias, 2006; Sebastianes Marfil, 1995; Herrera-Rodríguez, 2008; SotoVillalba, 2015; Marín-Paz,2013; FernándezLozano, 2018; Olagüe de Ros y ParedesSalido 1983, etc.).

En 1871, en pleno periodo del "sexenio democrático", aparece en Jerez de la Frontera la publicación que motiva nuestro artículo: la Gaceta Médico-Quirúrgica Jerezana (Góngora, 1900; Leiva, 1982), desde cuyas 
páginas se darán a conocer algunos casos de la experiencia clínica que su promotor, "Francisco Revueltas Carrillo Montel", y sus colaboradores, generaron en el centro asistencial donde desarrollaban su trabajo: el Hospital General de Santa Isabel de Jerez de la Frontera (figura 1). Incluyendo también casos de la actividad clínica privada de algunos de los autores que publicaron en la revista.

\section{FIGURA 1. Cabecera del primer número de la \\ Gaceta Médico Quirúrgica Jerezana, con observaciones recogidas en el Hospital General de Santa Isabel (15 de agosto de 1871)}

Año $\mathrm{I}$. MaATES 15 DE Agosto de 1871

GACETA MÉDICO-QUIRURGICA JEREZANA CON OBSERVACIONES RECOGIDAS EN EL HOSPITAL GENERAL DE SANTA ISABEL.

FUENTE: Biblioteca Central Municipal de Jerez de la

Frontera

Al estudio de esta revista jerezana dedicamos las páginas que siguen, planteándonos los siguientes objetivos:

- Ofrecer un índice cronológico de los contenidos de los 12 números localizados de la Gaceta MédicoQuirúrgica Jerezana, correspondiente a los años 1871-1872, reflejando en el mismo a los autores, los temas tratados y las noticias.

- Exponer datos sobre las primeras décadas de funcionamiento del Hospital de Santa Isabel de Jerez de la Frontera, especialmente en lo que se refiere a su fundación y a la década de los setenta del siglo XIX, por ser ésta la institución en la que algunos de los autores de la revista desarrollaron su labor asistencial y donde estudiaron casos clínicos que se exponen en las páginas de esta publicación periódica jerezana.
- Estudiar el contenido de la citada revista, subrayando las aportaciones de los autores y los principales temas que se tratan, así como comprobar la actividad docente realizada en el hospital jerezano. - Apuntar, en la medida que lo permitan las fuentes, el perfil ideológico plasmado en la revista, tanto en cuestiones médicas y quirúrgicas, como políticas y sociales.

Teniendo en cuenta estos objetivos vertebraremos nuestro artículo en los siguientes apartados: Breve nota sobre el Hospital de Santa Isabel de Jerez de la Frontera; Fundación, dirección y estructura de la Gaceta Médico-Quirúrgica jerezana; Autores y artículos publicados en la revista; Epílogo; Índice cronológico de la Gaceta Médico-Quirúrgica Jerezana (1871-1872); Fuentes documentales y Bibliografía.

\section{Breve nota sobre el Hospital de Santa Isabel de Jerez de la Frontera}

La desamortización de Mendizábal tuvo como consecuencia, en el año 1834, que los Hermanos Hospitalarios de San Juan de Dios tuvieran que abandonar el Hospital de la Candelaria de Jerez, motivo por el que el Ayuntamiento se planteó fundar a sus expensas un hospital público, "cosa que se hizo en el también desamortizado Convento de los Mercedarios, dando lugar al Hospital Municipal de Santa Isabel", que comenzó a funcionar a principios de la década de los cuarenta del siglo XIX (Mariscal-Trujillo, 2015) (figura 2). Efectivamente, en Cabildo de 23 de septiembre de 1841, punto 4. ${ }^{\circ}$, se precisa esta cuestión de la siguiente manera: "Viose un oficio de la Junta municipal de Benef. fha 21 del que rige dando parte de que para solemnizar del mejor modo posible la inauguración del hospital general de Santa Isabel que se ha erigido en el edificio que fue convento 
de Mercenarios (sic), ha acordado celebrar una función religiosa el próximo Domingo 26: lo que ponía en noticia del Ayto. por si gusta persidirla y avisar la hora que tenga por conveniente para hacer el convite de las corporaciones, autoridades y personas de distinción y designar el sitio de que haya salir el acompañamiento; y se acordó decir á la Junta que el Ayuntamiento la espera con el convite en el Consistorio para salir de él á las nueve de la mañana" (Legajo n. 339, expediente 9992, AMJF) (Cf. también a Doña-Nieves, 1987). Dos años después, en 1843, se comenzó el expediente para construir el Departamento de mujeres del hospital (legajo n. ${ }^{\circ}$ 342, expediente 10094, AMJF). Comenzando, al parecer, la asistencia a mujeres en 1846 (Doña-Nieves, 1987).

Durante la década de los cincuenta y la de los sesenta se realizaron varias obras y reparaciones en el hospital (Legajo n. 342 , AMJF). En mayo de 1853, la Superiora de las hermanas de la Caridad, Sor Tomasa Ochoa, realizó un escrito demandando que se enviasen más hermanas al hospital para el cuidado de los enfermos. Dice así: "A pesar de que por nuestras santas reglas la asistencia Hospitalaria debe estar en proporción de diez enfermos por hermana, (...), considerando la imposibilidad de practicar esta asistencia con la previa atención que cristiana y fisicamente tiene derecho á esperar el enfermo de las Casas Hospitalarias puestas al cuidado, y solicitud prescritas en el instituto que profesamos..." (Legajo N.o 340, expediente 10047, AMJF). Un documento, pues, de mediados del siglo XIX que señala dificultades para llevar a cabo la labor asistencial por parte de las hermanas de la Caridad.

Precisamente, el fundador de la Gaceta Médico-Quirúrgica jerezana, Francisco Revueltas, junto a Manuel Fontán Crespo y Francisco Javier Hernández, confeccionaron un reglamento del hospital, que vio la luz pública en 1874, señalándose que es un establecimiento que depende del Ayuntamiento y de los fondos que pertenecen a la Beneficencia y sus presupuestos. El hospital en ese momento está dividido en dos departamentos, uno para hombres y otro para mujeres. El departamento de hombres se divide en salas para personas con "enfermedades internas" (Medicina) y salas que se destinan para los que sufren "afecciones esternas" (Cirugía). Igualmente existe esta diferenciación, salas de medicina y salas de cirugía, en el departamento de mujeres, añadiéndose además un departamento para parturientas, que aparece dividido en dos ("uno para aquellas que carecen de todo recurso, y otro para las que contando con medios de subsistencia desean ocultar su falta á los ojos de la sociedad"). El hospital contaba también con un depósito general para cadáveres y sala de autopsia. Entre los profesionales al servicio del hospital se cita en el Reglamento a tres profesores de medicina y cirugía, con el haber anual de 1.500 pesetas cada uno, un farmacéutico con la misma cantidad, ración y casa, además de dos cirujanos sangradores "que desempeñan las funciones de primero $y$ segundo practicantes, con 1.200 pesetas y 900 pesetas igualmente anuales, racion y casa cada uno". El hospital contaba también con el servicio de tres topiqueros y una matrona, cobrando esta última diez pesetas por cada "parto natural" que asista. La Superiora de las hermanas de la Caridad "es hoy el Gefe económico-administrativo del Establecimiento y están á sus órdenes todos los empleados subalternos de las diversas secciones", además de otras funciones que se especifican en el Reglamento y que hemos expuesto en otro trabajo (Cf. Reglamento, 1874; HerreraRodríguez, 2008). Las hermanas de la Caridad parece que comenzaron a prestar sus servicios en el hospital en 1845, ya que 
de esa fecha existe un contrato de estas religiosas con la Beneficencia Municipal jerezana (Herrera-Rodríguez, 2008).

En 1860 ingresaron en el hospital 2.096 enfermos, de los cuales murieron 219 , siendo las enfermedades más frecuentes la tisis, las colitis crónicas y cánceres (Mariscal-Trujillo, 2001). Este estudioso jerezano cita también al historiador Caro-Cancela que afirma que en 1867 fueron asistidos en el hospital aproximadamente unas tres mil personas de las cuales fallecieron 252 (Mariscal-Trujillo, 2001; Caro-Cancela, 1990). Precisamente, la Gaceta Médico-Quirúrgica jerezana, ofrece un "Cuadro estadístico del movimiento ocurrido durante el año de 1871 en el Hospital General de Santa Isabel, de esta ciudad, a cargo de los profesores que suscriben", que son Manuel Fontán Crespo, Francisco J. Hernández, y el fundador y director de la revista Francisco Revueltas. En este documento se consigna que ingresaron en el hospital un total de 2.262 personas, de los cuales 1.898 eran hombres y 364 mujeres. Falleciendo un total de 170 personas. Se especifican las patologías tratadas en la sección de medicina y en la sección de cirugía, ofreciendo también una lista de las "operaciones practicadas de mayor interés", así como los partos asistidos en la sala de maternidad (Cf. GM-QJ 12, página desplegable). Un documento, pues, de gran interés que refleja la actividad asistencial en 1871, año en que comienza su publicación la Gaceta Médico-Quirúrgica Jerezana.

FIGURA 2. Entrada del Hospital Municipal de Santa Isabel de Jerez de la Frontera

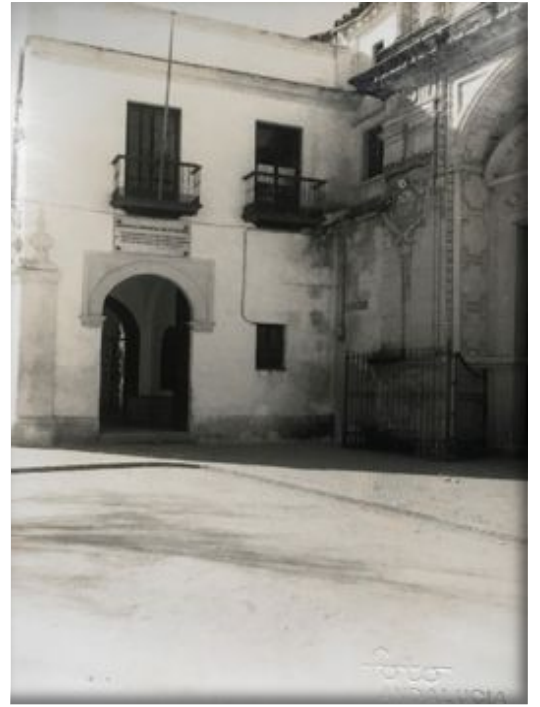

Fotografía incluida en una Memoria del año 1954.

Foto Andalucía (Legajo n. ${ }^{\circ}$ 1406-Expediente 27307 bis. AMJF)

\section{Fundación, dirección y estructura de la Gaceta Médico-Quirúrgica Jerezana}

Durante los años del sexenio democrático (1868-1874), observamos que se produce en la provincia de Cádiz un notable interés por impulsar el periodismo médico, siendo principalmente dos localidades en las que se publican las revistas de mayor interés; en el caso de Cádiz, encontramos que salen a la luz pública El Progreso Médico, en 1868, dirigida por el jerezano Juan José Cambas Gallego (1833-1877), que en esos momentos es profesor clínico de la Facultad de Medicina de Cádiz (Herrera-Rodríguez, 1994 y 2000), y La Crónica Oftalmológica que comienza a publicarse en 1871 con la dirección de Cayetano del Toro y Quartiellers (1842-1915), pionero de la Oftalmología en España y destacado político local (Orozco-Acuaviva, 1962 y 1980a; Herrera-Rodríguez, 2010; Guisado-Cuéllar, 2017; Fernández Lozano, 2018). En Jerez de la Frontera aparece, también en 1871, la Gaceta Médico-Quirúrgica Jerezana, fundada y dirigida por "Francisco Revueltas Carrillo y 
Montel" (1839-1887). En las tres revistas, en líneas generales, encontramos un rasgo común: la defensa de la libertad de enseñanza. Una libertad de enseñanza, en todos sus grados y clases, que fue promovida legalmente por Ruiz Zorrilla en un Decreto de 21 de octubre de 1868, quedando autorizados todos los españoles para fundar establecimientos de enseñanza, hecho que también quedó refrendado por la Constitución de 1869 (Puelles-Benítez, 1980).

Centrándonos en la revista jerezana hemos apuntado que su director y fundador fue el doctor Francisco Revueltas, figura a la que Orozco dedicó su atención en Bibliografía Médico-Científica gaditana (Orozco-Acuaviva, 1981d) y que cuenta con un excelente ensayo biográfico (Doña-Nieves, 1987a), motivo por el que solo trazaremos una breve semblanza de este médico jerezano. Su biógrafo ha señalado el asunto del nombre y apellidos del Dr. Revueltas, que con asiduidad utilizaba la firma, como en el caso de la revista que estudiamos, "Francisco Revueltas Carrillo y Montel". Su biógrafo lo explica así: "Es conveniente señalar el hecho de que, en dichos anuncios, aparece don Francisco con los apellidos de «Revueltas-Carrillo». No conocemos el origen del apellido «Carrillo» en la familia de Revueltas; si bien, es cierto, que su padre (quien, como, ya pudimos comprobar, se apellidaba Revueltas Chapé) lo había utilizado. El propio Dr. Revueltas Montel lo adoptaría (quizás como homenaje a su padre), y con él firma muchos de sus escritos (...). En consecuencia, en muchas ocasiones, es posible encontrar su nombre como "Francisco Revueltas Carrillo y Montel» (o, simplemente, «RevueltasCarrillo»)" (Doña-Nieves, 1987a). Quede constancia de esta circunstancia porque en la Gaceta, como decimos, aparece como "Revueltas Carrillo", "Francisco Revueltas Carrillo" y como "Francisco Revueltas Carrillo y Montel". En su expediente de alumno de la Facultad de Medicina de Cádiz, que consignamos en el apartado de fuentes documentales, que se conserva en el Archivo de la Universidad de Cádiz, consta como Francisco de Paula Revueltas y Montel, aunque en alguna ocasión también vemos que en este documento erróneamente se apunta "Montiel".

El doctor Revueltas nace en Jerez de la Frontera en 1839. Estudió la licenciatura y realizó el doctorado en la Facultad de Medicina de Cádiz. Se matriculó en el primer año de la carrera en 1856, obtuvo el grado de Bachiller en Medicina y Cirugía en septiembre de 1860 y el grado de licenciado en septiembre de 1862, con la calificación de Sobresaliente, con un tribunal constituido por los profesores José Gabarrón, Eugenio Rivera y José Villaescusa. Realizó las asignaturas de doctorado en la Facultad gaditana, en junio de 1869, obteniendo la calificación de aprobado en las dos asignaturas: Historia de la Medicina y Análisis Químico, y la calificación de Sobresaliente en el acto de grado de doctor, con un tribunal constituido por figuras notables de la medicina gaditana: Federico Benjumeda, Pascual Hontañón, Rafael Marenco, Juan Chape y Miguel Moreno. Lamentablemente, como señalamos hace unos años, no se conserva en su expediente de alumno de la Facultad de Medicina su Memoria para el doctorado, motivo por el que desconocemos al día de hoy el título del tema y el contenido de la referida tesis (Herrera-Rodríguez, 1987). Revueltas falleció tempranamente; a lo largo de su vida no debió gozar de buena salud, como ya ha apuntado Doña-Nieves, ya que a lo largo de la carrera estuvo enfermo en varias ocasiones y así lo certificaron diversos médicos (Doña-Nieves, 1987; Cf. también su expediente: FM 83 (1)-1, AUCA). No gozó de buena salud, sin embargo esta circunstancia 
no le impidió realizar una intensa actividad profesional como cirujano y una notable labor política como alcalde de Jerez y defender sus ideas republicanas (DoñaNieves, 1987). Recientemente, el historiador Diego Caro Cancela, ha publicado un notable ensayo titulado " $\mathrm{La}$ ciudad republicana: Jerez de la Frontera a finales de 1868", en el que apunta la composición de la Junta Revolucionaria de Jerez, constando como vocal Francisco Revueltas, médico, con militancia en el partido Demócrata (Caro-Cancela, 2018).

Revueltas centró su actividad médica en el terreno de la ginecología, tuvo especial interés en la ovariotomía e inventó incluso un modelo de uteroscopio, aunque como tendremos ocasión de comprobar en el seno del Hospital de Santa Isabel de Jerez realizó una importante labor en el Departamento de Cirugía, demostrando interés por las resecciones y amputaciones quirúrgicas. Impulsó la organización de Congresos Médicos en Andalucía (Doña NievesHerrera-Rodríguez, 1991). Realizó aportaciones en las que reivindica el uso higiénico terapéutico del vino de Jerez (Doña-Nieves, 1987a; Orozco-Acuaviva, 1981d; Doña-Nieves y Herrera-Rodríguez, 1990). Doña-Nieves, en su biografía, ha estudiado también su labor como Alcalde de Jerez, destacando la elaboración de un censo de población, la inauguración de la Biblioteca Pública Municipal, el inicio de las obras del Mercado Central de Abasto o, entre otras actuaciones, el impulso a la creación del Cuerpo de Médicos Titulares de la Beneficencia Municipal. Lamentablemente, Francisco Revueltas, falleció en 1887, cuando todavía se podía esperar mucho más de su labor médica, quirúrgica e incluso política. Efectivamente, el doctor Revueltas, que tenía domicilio en la Calle Corredera 27, falleció a los 48 años de edad, consignándose como causa de la muerte, en el libro de registro del cementerio, la "pleuropneumonía" (DoñaNieves, 1987) (Libro de Cementerio 53, 1887, f. 22, AMJF). No conocemos un retrato que reproduzca la imagen de Revueltas, hoy día tiene una calle céntrica en Jerez dedicada a su memoria (figura 3).

Centremos nuestros comentarios, una vez esbozada la biografía del doctor Revueltas, en los principales aspectos publicísticos y en la estructura de la Gaceta Médico-Quirúrgica Jerezana, como son los objetivos, las secciones que tenía la revista, cuestión esta última que en líneas generales ha sido apuntada recientemente (Soto-Villalba, 2015).

FIGURA 3. Calle céntrica dedicada al Dr.

Revueltas en Jerez

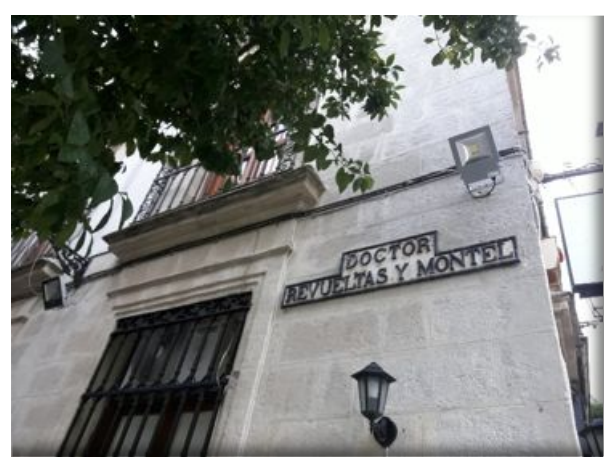

Fotografía: F. Herrera, 2019

Como se puede apreciar en el índice cronológico que acompaña nuestro trabajo, la revista normalmente solía estar constituida por las siguientes secciones, aunque en algunas ocasiones no se publicase una sección en concreto: artículos de la sección de medicina y cirugía, que reflejan la actividad de la Clínica Médica y de la Clínica Quirúrgica del Hospital de Santa Isabel, o de la actividad clínica privada de los autores; enfermos asistidos durante el mes corriente en el Hospital; informes de Francisco de 
Barea sobre el número de acogidos en el Hospicio Provincial de Jerez, señalando el número de personas existente al final del mes correspondiente, así como enfermos, curados y muertos; informes de Francisco G. Reguera sobre los albergado en la casa de expósito durante el mes de la fecha; informes de defunciones y nacimientos ocurridos en la ciudad en el mes, según datos suministrados por los jueces municipales; el estado sanitario de la ciudad; y un apartado de "varios" o de noticias, en las que se ofrece información sobre visitas al hospital, recomendaciones de libros, agradecimientos a otras revistas, fallecimientos de médicos como es el caso del profesor Antonio García Villaescusa, al que haremos alusión más adelante, o información sobre nombramientos o hechos que afectaban a asociaciones médicas en la provincia de Cádiz y en España. La periodicidad de la revista es mensual, localizándose en la Biblioteca Municipal de Jerez de la Frontera 12 números que abarcan desde el 15 de agosto de 1871, el número 1, al 31 de julio de 1872, el número 12; normalmente aparecía los días 15 de cada mes, circunstancia que cambia a partir del número 9 que aunque mantiene la periodicidad mensual ya no es fijo el día de $\mathrm{su}$ aparición. Al parecer, aunque hasta el momento no hemos tenido fortuna en su localización, en 1875 se publicaron seis números más de la revista (Góngora, 1900), motivo por el que centramos nuestro trabajo en los 12 números que aparecieron entre agosto de 1871 y julio de 1872. La revista se confeccionó en la "Imprenta Española", que tenía su domicilio en el número 2 de la calle de los Remedios de Jerez de la Frontera. Como hemos indicado el doctor Francisco Revueltas fue el director y fundador de la revista, contando con dos redactores principales: el propio Revueltas y el médico del Hospital de Santa Isabel Manuel Fontán y Crespo, sobre el que haremos algún comentario cuando expongamos los artículos que publicó en la revista. Además la publicación contó con colaboradores, que asimismo señalaremos cuando comentemos estas aportaciones.

En cuanto a los objetivos de la revista quedan claros en las secciones de la misma, pero además se precisan en el número 1, en un texto firmado por "La Redacción" que lleva por título "Artículo prospecto", en el cual se elogia la libertad de enseñanza, los avances de la física, de la química orgánica, la invención de aparatos como el oftalmoscopio que conlleva el avance de una especialidad como la oftalmología, pero sobre todo plantea un firme alegato en defensa de la "observación práctica" en la medicina (GM-QJ: I (1871), 1, pp. 1-5). Así lo expresan los redactores de la Gaceta, que no pueden ser otros que Revueltas y Fontán, aunque probablemente fuera el propio Revueltas, como fundador y director de la revista, el que escribiera el texto al que aludimos:

"Presentar, después de observados, los hechos recogidos; reunir todos los que ocurran en la práctica de cada uno, así como en el Hospital, fuente, pudiera decirse, de inagotable práctica, con el tratamiento, ya médico o quirúrgico, empleado; el proceder, si fue este último, ó el sistema á que se sujeto, si aquel fue: con las reflexiones que se nos ocurran sobre el caso, será el objeto primordial de esta publicación, que al fin del año formará un verdadero Álbum clínico".

Asimismo, muy conscientes de la importancia de la Estadística, "ciencia que de base sirve para la promulgación de leyes de sanidad é higiene", justifica plenamente que en la revista se incorporen secciones sobre el estado del Hospital de Santa Isabel de Jerez, 
mensualmente, en cuanto los nacimientos, defunciones, clasificación de sexos y edades, o que "el estudio del estado sanitario de esta población no quedará olvidado; y para que este sea exacto, y sus causas, ya climatológicas atmosféricas ó de localidad conocidas, abrigamos la esperanza que nuestros compañeros habrán de ayudarnos, con sus noticias y con sus trabajos de observación; para los cuales, como para todos, quedan abiertas las columnas de este periódico".

Un claro afán modernizador y regeneracionista se aprecia, pues, en las intenciones de Francisco Revueltas con la publicación de esta revista, en Jerez de la Frontera, en los años 1871 y 1872, años de efervescencia que preceden a la I República española, de la que en Jerez el propio Revueltas como se ha apuntado fue un protagonista destacado. No se debe olvidar las dificultades económicas por las que pasó la Gaceta Médico-Quirúrgica Jerezana para sacar a la luz pública estos 12 números, sobre todo en lo que se refiere al pago de las suscripciones, al respecto se apunta lo siguiente en la revista: "Los inmensos perjuicios que esta empresa está sufriendo con la morosidad de muchos de los suscritores, que aun no han satisfecho sus descubiertos, á pesar de haber recibido todos los números publicados, nos ponen en la precisión de advertirles, que si antes de la publicacion del próximo número no remiten á la administración el importe de sus suscriciones en libranzas del giro mútuo ó sellos de correo, los borraremos de la lista de suscritores, y por consiguiente, dejarán de recibir el periódico" (GM-QJ: I (1872), 8, p. 189).

\section{Autores y artículos publicados en la revista}

Desgranamos en este apartado el contenido de la revista, en lo que se refiere a autores y temas publicados, sin olvidar una dimensión que consideramos importante $\mathrm{y}$ que pensamos debe ser estudiada en el contexto de la libertad de enseñanza que propició el sexenio democrático, nos referimos a la enseñanza clínica que se llevó a cabo en el Hospital de Santa Isabel de Jerez de la Frontera en estos años, ya que algunos de los autores de los artículos son alumnos de medicina que en esos años realizaban la carrera, como tendremos ocasión de ver, en la Facultad de Medicina de Cádiz, pero a la vez desarrollan sus prácticas en el hospital jerezano, reflejándose esta actividad en las citadas publicaciones. En primer lugar centraremos nuestros comentarios en las publicaciones de Revueltas Carrillo, Fontán Crespo, Federico Rubio y otros médicos que dejaron su firma en la revista y que quedan apuntados en la siguiente tabla, en la que se precisa el nombre de los autores, el número de los artículos y el número de páginas que ocupan sus artículos en la revista (tabla 1). No contemplamos en este apartado los informes estadísticos realizados por Francisco de Barea y Francisco G. Reguera, correspondientes al hospicio y a la casa de expósitos, ya que consideramos que el análisis de esta información debe ser analizada en futuros trabajos. 
TABLA 1: Nombre de los autores (médicos) que publicaron en la revista, número de artículos publicados y número de páginas de cada autor en la revista

\begin{tabular}{|l|c|l|}
\hline \multicolumn{1}{|c|}{$\begin{array}{c}\text { NOMBRE DEL AUTOR } \\
\text { (MÉDICOS) }\end{array}$} & $\begin{array}{c}\text { NÚMERO DE } \\
\text { ARTÍCULOS } \\
\text { PUBLICADOS }\end{array}$ & $\begin{array}{c}\text { NÚMERO DE PÁGINAS } \\
\text { EN LA REVISTA }\end{array}$ \\
\hline FRANCISCO REVUELTAS CARRILLO & 4 & 41 y página desplegable \\
\hline MANUEL FONTÁN CRESPO & 2 & 11 y página desplegable \\
\hline LEONARDO NAVAS ROMÁN & 1 & 12 \\
\hline JOSÉ ANTONIO REYNÉS & 1 & 8 \\
\hline FEDERICO RUBIO Y GALÍ & 1 & 38 \\
\hline DR. GERARD & 1 & 6 \\
\hline JUAN J. CORTINAS & 1 & 18 \\
\hline PEDRO RUIZ BERDEJO & 1 & 4 \\
\hline JUAN JOSÉ CAMBAS GALLEGO & 1 & 2 \\
\hline FRANCISCO J. HERNÁNDEZ & - & Página desplegable \\
\hline
\end{tabular}

FUENTE: Gaceta Médico-Quirúrgica Jerezana (1871-1872)

\section{1. "Francisco Revueltas Carrillo y Montel"}

El doctor Francisco Revueltas publicó tres artículos en la revista y también es autor de la necrológica dedicada a su maestro en la Facultad de Medicina de Cádiz, Antonio García de Villaescusa, que aparece publicada en varios números, constando como veremos en la primera parte de este escrito la firma de Revueltas, de ahí que le atribuyamos la totalidad de este texto y computemos un total de 4 trabajos, aunque con seguridad redactaría otros apartados de noticias y comentarios que aparecen en la revista de forma anónima.

El primer trabajo firmado por Revueltas lleva el título de "Croup. Traqueotomía" (GMQJ: I (1871), 1, pp. 5-12). No se debe olvidar que "Revueltas Carrillo" tenía a su cargo la clínica quirúrgica del Hospital de Santa Isabel, institución en la que venía desarrollando su labor desde 1864 (DoñaNieves, 1987a), aunque también realizó el ejercicio particular de la medicina aportándole casos clínicos de interés. Lo primero que aclara es que estas observaciones clínicas ya fueron publicadas en el periódico El Progreso Médico de Cádiz, dirigido por el jerezano Juan José Cambas. Revueltas justifica la reproducción de este trabajo por varias razones: la polémica que sobre el tema se ha producido en la Real Academia Nacional de Medicina y dar a conocer una nueva observación clínica obtenida en la clínica del hospital, afirmando que "son las únicas que pueden recogerse en esta provincia, donde solo por mí se ha practicado".

La primera historia clínica corresponde a una niña, J.R.G., de tres años y medio de edad, que "fue invadida del croup en Chiclana", en agosto de 1868. El primer médico que la atendió fue el Dr. Jiménez, en la casa donde se alojaba la familia (calle Medina 1), hizo el diagnóstico y prescribió sangrías, vomitivo y sinapismo. Mejoró, pero al día siguiente la salud de la niña empeora y el Dr. Jiménez avisa a Revueltas que acudió al domicilio citado con los médicos José Piñero, Cristóbal Mateos y Aldolfo de la Rosa, "y no habiendo tiempo que perder por hallarse la enferma casi asfitica, practiqué por primera vez la 
traqueotomía, sorprendiéndome agradablemente el resultado tan satisfactorio obtenido por ella". Mejoró en los cinco días siguientes, "hasta el sesto en que, olvidado su madre cerrar las puertas de un balcón, paralelas á las de la alcoba en que la enfermita se hallaba, fue esta acometida de un catarro perineumónico, que concluyó con su vida, ya salvada del croup, al sesto dia de haber sufrido la operación".

La segunda historia clínica corresponde a un niño de 14 meses de edad, N.N., Revueltas acompañado de su compañero del Hospital, Manuel Fontán, y del profesor Juan Lomón, realizó la traqueotomía, falleciendo el pequeño catorce horas después de practicada la operación. El tercer caso corresponde a un niño de 28 meses, A.G., Revueltas también llevó a cabo la traqueotomía. Así lo explica el médico jerezano: "Pasados ya cuarenta de la operación, y no habiendo tenido que combatir ningún accidente durante ellos, y hallándose el niño, si bien débil, en las mejores condiciones, la abatí por completo. Un grito que siguió a la separación de la cánula, el llanto ya sonoro y algunas balbucientes palabras, me hicieron comprender que el aire seguía bien y sin obstáculos á su paso el conducto natural, que las cuerdas vocales eran heridas por él y que no había peligro en cerrar la herida (...). A las treinta horas, la herida de la traquea se había unido por completo, faltando solo por unir la esterna, que á los cuatro días tuve que cauterizar". Según apunta Revueltas el pequeño falleció como consecuencia de "los bruscos cambios de temperatura que en este mes de Diciembre se sucedieron, á una gran congestion fuerte del cerebro, que acabó con su vida".

Un discípulo de Revueltas, Balbás, del cual más adelante ofreceremos datos biográficos, narra otro caso de traqueotomía realizada por el cirujano de Jerez que también tiene un final desgraciado (GM-QJ: I (1871), 1, pp. 1217). Sin embargo, el mismo discípulo meses después, escribió una crónica en la que da cuenta del éxito obtenido por el doctor Revueltas al practicar la traqueotomía siguiendo el método de Trousseau a una niña de 5 años, M.A.C., que vivía en la casa número tres de la calle Ponce de Jerez (GMQJ: I (1872), 11, pp. 272-279). Es importante resaltar este éxito quirúrgico del Dr. Revueltas, ya que Cayetano del Toro en 1879, refiriéndose a Cádiz, afirmó que la casuística de las traqueotomías practicadas arrojaba un balance muy negativo. Según este importante médico gaditano en la ciudad de Cádiz se había practicado la operación en veinte ocasiones, cinco de las cuales realizadas por él mismo. Sólo uno de estos veinte niños operados, intervenido por José de Dios, salvó la vida (HerreraRodríguez, 2000).

Después de todo lo apuntado se comprende que en sus reflexiones sobre el "croup diftérico" el doctor "Revueltas Carrillo" se muestre partidario de la traqueotomía, aunque es consciente que ésta no cura la enfermedad, "es solo un medio por el cual se consigue paralizarla, detenerla en su camino (...). Facilitando la entrada del aire, de un aire puro, nuevo respirable, pues no vá cargada de moléculas, detritus ó miasmas, que ha de llevar en si indudablemente el que atraviesa la laringe y traquea, ya afectas al mal, se evitará la formación de nuevas placas ó falsas membranas en el resto de la mucosa". Revueltas de todas las técnicas de la traqueotomía destaca la de Trousseau, que se realiza disecando los tejidos blandos, capa por capa, ligando los vasos cortados, y la de Chassaignac con la que "se hieren todos los tegidos de un solo golpe, punzando primero y cortando despues los anillos precisos de la traquea". En los tres casos, Revueltas aplicó la técnica de Trousseau. Añade "Revueltas Carrillo" que el "croup" puede ser ascendente o descendente; en el primer caso, o sea en la angina diftérica, se 
decanta por las cauterizaciones usando el nitrato de plata sólido, "á cuyo tratamiento debo curaciones múltiples de enfermos"; en el segundo caso, se decanta por la traqueotomía. En cuanto a sus reflexiones etiológicas el médico jerezano señala que "si el croup es debido á un criptógama, según los micrógrafos, de notar es, que siempre se observa epidémicamente y en ciertas épocas y estaciones: parece que existe algo en la atmósfera, especial, distinto y nuevo en ella, que lo produce".

Otra aportación de Francisco Revueltas en la revista es su artículo "Resección y amputaciones", que publicó fragmentado en cinco entregas de unas cuatro páginas cada una de ellas (Cf. GM-QJ: I (1871), 2, pp. 2528; I (1871), 5, pp. 101-104; I (1872), 7, pp. 157160; I (1872), 9, pp. 221-224; I (1872), 11, pp. 269-272). Revueltas trata de analizar las ventajas de la resección, por ejemplo, en las caries de los huesos, en las fracturas con separación de fragmentos o grandes esquirlas, en los "tumores blancos" y en los osteosarcomas; cree indispensable la amputación en la gangrenas de las extremidades causadas por el traumatismo, "en que la naturaleza también por sí misma separa lo que la estorba y le es ya indiferente, porque perdió las cualidades precisas para afectar aquella forma de vida". Una cuestión que cree imprescindible el médico jerezano es definir lo que se entiende por resección y lo hace así: “...la separación de cualquier hueso en todo su espesor ó en parte, en toda su longitud ó en parte de ella, comprenda la articulación, ó sea solo una esquirla, siempre que queden los tegidos blandos que lo rodean y el periósteo; en una palabra, la separación por el arte de algún trozo del esqueleto: distinguiéndose de las amputaciones, en que por estas se separa del cuerpo humano una parte de él en que se comprenden todos sus componentes, duros y blandos". En la decisión de practicar una cirugía conservadora, preferible siempre que se pueda, frente a la cirugía radical de la amputación, debe estar en el ánimo y en la inteligencia del cirujano el que peligre o no la vida del paciente, siendo esto así habrá de decantarse por la "mutilación". Revueltas preconiza que para alcanzar un buen resultado con la resección es preciso "que el periósteo se conserve, por ser á él al que habrá de deberse la formación del nuevo tegido oseo, que reemplace al separado, lo cual no todas veces es posible, ni fácil conseguir". Pero en muchas ocasiones el "periósteo" participa del mismo mal que el hueso, al que tan íntimamente está unido y del que es matriz: "los mismo trayectos fistulosos que en este se encuentran; la misma degeneración que en él se halla, se vé en aquel, y de nada serviría separar uno, dejando el otro acaso, con todo el elemento morbífico; habiendo necesidad entonces de eliminar ambos. Y si esto no perjudica demasiado para la regeneración osea, siendo pequeña la porción de periósteo secuestrada, perjudicará si lo es en mucho". Advierte también que si el diagnóstico no es exacto, "si creemos local y traumático lo que obedece á un vicio general y es solo sintomático de una afeccion, la operación que se practique será inútil; la herida hecha perderá bien pronto sus caracteres de sanidad, empezando á cubrirse de todos aquellos que antes tuvieran las úlceras que rodearan el hueso necrosado y secuestrado".

Este artículo sobre la resección y las amputaciones nos ha hecho recordar que en 1861, 1862 y 1876, el cirujano Federico Rubio mantuvo una polémica con los cirujanos Juan Creus Manso y Antonio Gómez Torres, polémica a la que dedicó un trabajo monográfico el profesor Albarracín Teulón. En esta polémica Federico Rubio negaba dos tesis sostenidas por los médicos "periostistas"; el cirujano portuense no creía que los huesos destruidos por el traumatismo, por la caries, necrosis, $\mathrm{u}$ otras causas, se reproduzcan o regeneren por el periostio y que las resecciones óseas deban 
hacerse separando el hueso de su periostio, para conservar éste íntegro y que por él se regenere el hueso (Albarracín-Teulón, 1975). Como se puede apreciar el artículo de Revueltas Carrillo publicado en la Gaceta, en 1871 y 1872, está con algunas cuestiones planteadas en el corazón de la polémica que sostenían estos cirujanos sobre el tema en las décadas de los sesenta y de los setenta del siglo XIX.

La tercera aportación de Revueltas en la revista no es muy extensa y está motivada por la obra del Dr. P. F. da Costa Alvarenga, médico de Lisboa, titulada "De la Thermosémiologie et thermacologie analise de la loi Thermo-differentielle" (Cf. GM-QJ: I (1872), 10, pp. 262-264). El comentario versa, como se puede apreciar por el título de la obra, sobre la termometría como método diagnóstico, el valor del termómetro y de las curvas térmicas. El comentario de Revueltas es muy escueto, aunque suficiente para comprobar que en las páginas de la revista también tuvieron cabida algunas líneas en las que se expone el diagnóstico fisiopatológico, expresándose de la siguiente manera: "Como se vé, el Dr. Alvarenga no se ha dejado seducir por las curvas térmicas: las dá solo el valor que deben tener: no pretende que el termómetro en la mano del médico sea el que precise el mal, sino el que ayude á esclarecerlo".

Otro escrito de "Revueltas Carrillo" en la Gaceta es la necrológica titulada "D. Antonio García de Villaescusa, Doctor en Medicina y Cirugía, catedrático y Decano de la Facultad de Cádiz". Lo justifica así: "Por esto no hemos querido renunciar al deber y al gusto de trazar, aunque condensándolos y á grandes rasgos los hechos acometidos y realizados por el que fue nuestro Maestro y al que tantas distinciones debimos". Efectivamente, si el lector tiene curiosidad de repasar el expediente académico de alumno en la Facultad de
Medicina de Cádiz del Dr. Revueltas, podrá comprobar que García de Villaescusa fue su profesor de "Anatomía Quirúrgica, operaciones, apósitos y vendajes". La necrológica realizada por Revueltas se presenta en la revista en tres números ocupando unas diez páginas (GM-QJ: I (1872), 7, pp. 182-185; I (1872), 8, pp. 211-214; I (1872), 9, pp. 241-242). García de Villaescusa nació en Alicante e ingresó con 19 años de edad "en el extinguido Colegio de Medicina y Cirugía de Cádiz". Según apunta Revueltas se graduó de licenciado en Cirugía médica el 24 de septiembre de 1818, recibiendo el mes de octubre del mismo año la "borla de doctor". Fue destinado a varios buques de guerra, hasta 1819, en que se le destinó al navío Alejandro I con rumbo a Lima. La navegación duró cien días y regresó a Cádiz "sin haber perdido un solo hombre". Pero en ese mismo año, en Cádiz, actuó como médico en la epidemia de fiebre amarilla. Fue nombrado por la Junta Suprema de Sanidad para comisiones relativas a la epidemia y "asistió durante toda la época calamitosa á los enfermos pobres de los barrios de Santa María y Candelaria", lo que motivó según apunta Revueltas que fuera inscrito su nombre en las actas capitulares "para ejemplo y noticia de la posteridad". El 22 de diciembre de 1820 se licenció en medicina, "cuyo título le fue reconocido por la Junta Superior de Medicina y Cirugía en 19 de abril de 1830". En mayo de 1821 fue nombrado segundo profesor de la Armada, cargo que desempeñó hasta fines de 1823. Nos encontramos en pleno periodo del trienio liberal: "El Doctor García de Villaescusa tomó una muy activa en esta lucha de la idea antigua con la idea moderna, del pasado con el porvenir, siendo uno de los que, con más valor, más fé y más abnegación la sustentaron: y sin olvidarse de aumentar cada dia más y más sus conocimientos médicos, sin separarse nunca del 
ejercicio de su profesión, propagaba con ardor los principios regeneradores...". Revueltas señala que García de Villaescusa sufrió la persecución política del absolutismo lo que le llevó al exilio en el extranjero; primero en Londres, donde asistió a las lección y a las clínicas de profesores eminentes, hasta el año 1824, en que se trasladó á París, y más tarde a Montpellier, donde obtuvo el 8 de enero de 1825 el grado de doctor "y quedó incorporado en el Cláustro de aquella Universidad". García de Villaescusa "entró de lleno en el sendero del racionalismo filosófico", presentando en la Facultad de Medicina de Montpellier, la siguiente tesis: "¿La doctrina de la irritación es quizá aplicable á la inteligencia y al tratamiento de las fiebres intermitentes perniciosas?". Lamentablemente, este esbozo biográfico tan interesante sobre la figura de Antonio García de Villaescusa, queda truncado en la página 242 de la revista, aunque se anuncia su continuación, aún así las páginas publicadas son de gran interés para reconstruir parte del perfil biográfico de este médico alicantino que durante tantos años fue médico y docente en Cádiz, del cual también realizó un perfil biográfico su discípulo el afamado cirujano Federico Rubio y Galí, concretamente sobre su labor docente, su carácter y algunos tristes episodios familiares, haciendo hincapié en su fervor revolucionario: "Villaescusa era el representante del elemento revolucionario en la ciencia, dentro de la Escuela Gaditana. Había estado, después de médico, en París; asistió a las clínicas de sus hospitales, alcanzó las postrimerías de Dupuytren, hizo amistades con Velpeau, Roux y otros profesores famosos y traía el espíritu impregnado de las reformas de la época" (Rubio y Galí, 1977). En 1868, Federico Rubio, le dedicó a Antonio García de Villaescusa su libro sobre los quistes y tumores del ovario, haciendo constar en la dedicatoria: "He recibido de usted mucha parte de mi instrucción quirúrgica; he recibido también, grandes pruebas de consideración y cariño..." (Herrera-Rodríguez, 2002a).

No queremos dejar de mencionar que cuando se ofrece la noticia del fallecimiento de García de Villaescusa, en una nota previa a la necrológica que hemos comentado, con el título "D.E.P." (Descanse En Paz), se realiza la crónica del entierro del citado profesor, durante el cual hizo la oración fúnebre el profesor Juan Ceballos Gómez (1817-1875) (Herrera-Rodríguez, 2000), y en representación de La Crónica Oftalmológica su director Cayetano del Toro depositó una corona sobre el féretro. Apunta lo siguiente el cronista: "...pronunciando aquel, al hacerlose refiere a Cayetano del Toro-, algunas palabras en elogio del Dr. García de Villaescusa, de su vida y de sus hechos; pero hiriendo con ellas la reputación tan justamente adquirida como gloriosa del célebre, eminente é inmortal Broussais, lo cual, á la verdad, no creíamos preciso; pues para estimar en lo que vale-que es mucho- el trabajo sobre fiebres intermitentes escrito por el Dr. García de Villaescusa en su juventud, atacando la doctrina fisiológica en sus puntos vulnerables, ¿a qué herir y lastimar ante personas, la mayor parte agenas á la facultad, un nombre, que si unos pronuncia con indiferencia, otros lo hacen con veneración y respeto? $\mathrm{La}$ humanidad entera debe mucho á Broussais, y los médicos modernos la base de nuestros juicios, que levantamos sobre las de racionalismo por él establecidas: sus tratados flecmasías crónicas y de irritacion y locura, serán siempre monumentos científicos, que ni la sátira, ni el escalpelo crítico más fino, ni el tiempo podrán destruir. Broussais en medicina, aparecerá en todas épocas, en el presente $y$ en el porvenir, como el gran innovador..." (GM-QJ: I (1871), 5, pp. 127128). Una polémica que continuó en el número siguiente de la Gaceta, en contestación a Cayetano del Toro, de la que merece ser destacado este párrafo: "En 
cuanto á la pregunta que al final de su suelto nos dirige, podemos decirle, que el profesor que ejerció en esta poblacion en la época de Broussais estuvo en ella asistiendo precisamente el Hospital que hoy visitamos, nos es conocido por algunos de sus escritos inéditos que aún se conservan en poder del Dr. Don Manuel Ruiz de la Rabia, que posee tambien su retrato, y que fue uno de los admiradores de D. Juan Ferran" (GM-QJ: I (1872), 6, pp. 155-156).

Asimismo, como hemos hecho constar, Revueltas, junto a Manuel Fontán Crespo y Francisco G. Hernández, en el último número de la Gaceta publicaron una página desplegable resumiendo a modo de cuadro estadístico la actividad realizada durante el año 1871, tanto en la sección de medicina como en la de cirugía, en el Hospital General de Santa Isabel de Jerez de la Frontera (GMQJ, I (1872), 12, página desplegable).

\subsection{Manuel Fontán Crespo}

Manuel Fontán Crespo consta en la revista como redactor, junto a Francisco Revueltas Carrillo Montel, y consta también como médico del Hospital de Santa Isabel, institución en la que estaba a su cargo la sección médica (Cf. este dato en GM-QJ, I (1871), 4, p. 94). Desconocemos cuando comenzó a prestar sus servicios en el hospital, aunque sí sabemos que renunció a su cargo en 1882, como consta en Acta Capitular, en el punto tercero de la sesión ordinaria del día 6 de noviembre. En la sesión extraordinaria de 22 de noviembre (punto 9.o) se nombró Facultativo interino del hospital a don Teodoro Orozco (Cf. Acta capitular 1882-1883, n.. 279, AMJF). Hemos intentado localizar un posible expediente de Manuel Fontán Crespo como alumno de la Facultad de Medicina de Cádiz que nos pudiera ofrecer información sobre el lugar y fecha de nacimiento, así como sobre su carrera, pero ha sido infructuosa nuestra consulta en el Archivo de la Universidad de Cádiz al no aparecer este expediente, lo que nos hace pensar que no realizó los estudios de medicina en Cádiz, aunque esta cuestión habrá que aclararla en futuras investigaciones.

Además de la página desplegable sobre estadísticas del hospital en el año 1871, a la que hemos aludido anteriormente, firmada por Revueltas, Hernández y el propio Fontán, observamos que este último publicó en la Gaceta dos artículos. El primero de ello, con el epígrafe general de "Clínica Médica del Hospital", se titula "Peritonitis aguda difusa. Curación" (GM-QJ: I (1871), 2, pp. 2833). Se trata de la historia clínica de L.G.R., de 51 años de edad, natural de Málaga, de oficio cantero, con antecedentes de enfermedad venérea en su juventud y que "ha hecho uso con exceso de bebidas alcohólicas". De madrugada el paciente sufre un fuerte dolor de vientre y vómitos. Se expone la evolución clínica entre el 23 de agosto y el 1 de septiembre de 1871, así como el tratamiento utilizado a lo largo de los días señalados: 36 sanguijuelas en el hipogastrio, cataplasmas, enemas emolientes, dieta vegetal, solución gomosa, un grano de calomelano cada dos horas, un dracma de ungüento mercurial doble, hielo, fomentaciones emolientes templadas, dos onzas de julepe moscado de Fuller. Se va anotando la mejoría progresiva hasta el 1 de septiembre en que se aumenta la ración. El artículo se complementa con reflexiones sobre la peritonitis, que según Fontán "puede confundirse á menudo con un cólico intestinal o hepático; con un cálculo biliar ó renal; con el cólera esporádico, etc.". A Fontán no le cabe duda que en este paciente "la flecmasia peritoneal había producido en la cavidad ventral un derrame seroso, y á más esas exudaciones tan comunes en las flecmasias de las serosas". En sus 
reflexiones también hace alusión a las peritonitis por causas traumáticas, en las hernias estranguladas, "en las puérperas y en otros casos de traumatismo".

El segundo artículo de Manuel Fontán versa sobre "Pústula maligna. Curación" (GM-QJ: I (1871), 5, pp. 109-113). Se trata de un hombre de 40 años de edad, de oficio panadero, que estando en el cortijo Romanina la Alta notó un tumorcito en la cara, "sobre la parte media é izquierda del borde inferior de la mandíbula inferior". Al hacerle la historia clínica el paciente refirió "que dos días antes de sentirse el grano en la cara había muerto en dicho cortijo una res de la enfermedad llamada lobado (carbunco)". No había comido su carne, ni estuvo en contacto con la piel, solo había estado junta a ella. El grano fue hinchándose y un médico le recetó una cataplasma emoliente y poco después se le realizaron sangrías. Se describe la evolución clínica, así como el tratamiento con una poción cordial compuesta de tres onzas de agua de mental, una dracma de la confección cordial de la Hispana y una onza de jarabe de naranjas, a dosis de una cucharada grande cada dos horas, una onza de quina en polvo en "seis papeles", "y vino de Jerez una cucharada en cada taza de caldo de tres en tres horas y disposición espiritual, pues se consideraba el caso perdido". En los días siguientes continuó la reacción y se le notó en el cuello y parte anterior del pecho manchas grandes rojizas. Se le suspendió el vino y la poción cordial, y continuó el tratamiento con la quina. Dos días después se fueron regularizando todas las funciones, desapareció la fiebre y el apetito, "y la enfermedad está reducida á las manchas que sobre el cuello y parte anterior del pecho se esfacelan". Se hicieron curas con vino aromático, y posteriormente al haber empezado a desprenderse varias escaras con miel y quina. A mediados de noviembre se considera que está curado, sin otra lesión que varias cicatrices superficiales en el cuello y parte anterior y lateral del pecho.

Fontán acompaña la historia clínica de reflexiones en las que señala que se usan como sinónimos las palabras carbunco y pústula maligna " $y$ que no se tienen ideas exactas sobre el modo de evolución de estas enfermedades y sus diversas tendencias; por mas que puedan ser una en su génesis: es decir, que pueda ser uno el mismo virus que los engendra". Añade que cuando se examinan atentamente a los enfermos se descubre casi siempre que la afección ha sido transmitida por un animal muerto de "lobado" o carbunco. Unas veces han comido la carne, otras veces "se han absorbido los miasmas ó virus carbuncoso por la respiración y aun las vías digestivas". Precisa Fontán sobre la cuestión algo más: "Cuando por haber desollado alguna res muerta de carbunco, ó por haber estado en contacto con restos de la misma, ó por haber sufrido alguna picadura de alguna mosca ó insecto sobre algún punto de piel fina $y$ al contacto de los agentes exteriores como las manos, el cuello, la cara, etc., la enfermedad se desarrolla localmente, y es despues de varios días de afecto local cuando penetrando el virus en el organismo vienen los sintomas generales. Aquí hay dos formas bien diversas. Una la pústula maligna, otra el carbunco idiopático".

\subsection{Una firma invitada: Federico Rubio y Galí (1827-1902)}

Federico Rubio es una de las figuras más notables de la cirugía española de la segunda mitad del siglo XIX. Nació en El Puerto de Santa María, estudió medicina en Cádiz, ejerció en Sevilla y en Madrid, pero adquirió también experiencia clínica en Francia y en Inglaterra, no debemos olvidar que sus ideas políticas republicanas le llevaron al exilio, circunstancias que aprovechó para formarse con cirujanos 
como Velpeau, Broca, Nelaton y Fergusson, realizando también estudios de microscopía en París con Eloy Carlos Ordóñez. Estos aspectos sobre su vida y obra son suficientemente conocidos, motivo por el que no nos extendemos y remitimos a la bibliografía (Gutiérrez, 1903; Álvarez-Sierra, 1947; Sánchez de la Cuesta, 1949; LaínEntralgo, 1977-1978; Orozco-Acuaviva, 1977; López-Piñero, 1983; HerreraRodríguez, 2000, 2002a, 2002b; Carrillo, 2002; Carrillo, 2003).

En un primer acercamiento a la Gaceta Médico-Quirúrgica Jerezana llama la atención la firma de Federico Rubio y Galí, con una colaboración especial titulada "Apuntes de don Federico Rubio y Gali sobre los tumores y quistes del ovario y el resultado de su tratamiento médico-quirúrgico", un trabajo que aparece en ocho números de la revista (GM-QJ: I (1871), 3, pp. 54-61; I (1871), 4, pp. 82-84; I (1871), 5, pp. 106-109; I (1872), 6, pp. 141-144; I (1872), 7, pp. 162-166; I (1872), 8, pp. 192-194; I (1872), 9, pp. 224-228; I (1872), 11, pp. 279284). En total Federico Rubio, en los citados números, publica 21 historias clínicas sobre el particular. Al revisar con detalle estas historias clínicas se puede comprobar que estas pertenecen a una publicación previa del autor portuense, nos referimos a su obra publicada en Sevilla "Apuntes de mi práctica sobre los tumores y quistes del ovario, y el resultado de su tratamiento médico y quirúrgico" (Rubio y Galí, 1868). En esta monografía Rubio publica 24 observaciones clínicas, las 21 primeras son precisamente las que aparecen publicadas nuevamente en la Gaceta Médico-Quirúrgica Jerezana. Entre estas observaciones clínicas debemos destacar la número 20, en la que se describe el caso de una mujer de 27 años, M.O., soltera, que consultó a Federico Rubio en junio de 1863. Fue diagnosticada de numerosos quistes voluminosos, acompañados de tumores fibrosos. El cirujano portuense realizó la primera ovariotomía, aunque finalmente la paciente falleció (GM-QJ: I (1872), 9, pp. 224-228). Este caso clínico, por su importancia, lo hemos descrito con detalle en otro trabajo. Federico Rubio, en la misma década de los sesenta, operó a una mujer de Osuna de un quiste y tumor fibroso en el ovario izquierdo y en esta ocasión coronó con éxito esta intervención quirúrgica (HerreraRodríguez, 2000). Se ha señalado que fue precisamente Federico Rubio el que practicó por primera vez en España la ovariotomía en el año 1863. Entre los años 1863 y 1887 se realizaron en España 120 ovariotomías, destacando en su práctica cirujanos como Eugenio Gutiérrez, Cardenal, Gómez Torres, Manrique, Losada, Revueltas, Devesa, Ferreras, Pérez, Vidal, Rodríguez, Navarro, Bonet, Formiguera, Castillo, Mas, Cantó, Candela, Camisón, Mariani, Cárceles y Arpal (Guedea-Calvo, 1890; HerreraRodríguez, 2000). Efectivamente, Francisco Revueltas, director y fundador de la Gaceta Médico-Quirúrgica Jerezana, destacó como cirujano, especialmente en Ginecología, y como ha señalado su biógrafo realizó la operación de la ovariotomía en 1875, "convirtiéndose así en el primer médico que la efectuó con éxito en nuestra provincia", describiendo la operación en un folleto titulado "Apuntes sobre una operación de ovariotomía verificada con feliz éxito el 10 de julio de 1875" (Doña-Nieves, 1987, pp. 39-40).

\subsection{Otros autores}

Según podemos apreciar en la tabla 1, además de Francisco Revueltas, Manuel Fontán y Federico Rubio, autores de los cuales ya hemos comentado sus trabajos, en la revista también publicaron otros médicos y cirujanos que exponemos dentro de este apartado. El primer autor que vamos a 
señalar es Juan J. Cortinas que publicó en la revista un artículo amplio, en seis entregas, titulado: "Hidrología Médica. De la influencia del agua en la naturaleza humana, como medio higiénico y como agente terapéutico" (GM-QJ: I (1871), 4, pp. 79-81; I (1871), 5, pp. 104-106; I (1872), 6, pp. 139-141; I (1872), 7, pp. 160-162; I (1872), 8, pp. 189-191; I (1872), 10, pp. 245247).

Juan José Cortinas Pérez nació en Jerez de la Frontera en noviembre de 1829. Estudió en el Instituto de su ciudad natal el bachillerato en Filosofía, título expedido en 1847. Estudió medicina en la Facultad de Cádiz comenzando la carrera en 1847, examinándose del grado de Bachiller en Medicina y Cirugía en 1852 y del grado de licenciado en junio de 1854. Se doctoró también en Cádiz, en 1869, con la calificación de Sobresaliente con una Memoria titulada " $¿ E l$ hombre es cosmopolita?". (Cf. Expediente de Juan José Cortinas en la Facultad de Medicina de Cádiz; Herrera-Rodríguez, 1987).

Cortinas en su artículo sobre la hidrología médica realiza unos apuntes sobre las características físico-químicas del agua y la importancia de la misma en el cuerpo humano, destacando entre otros autores los experimentos de Lavoissier y de Seguin que han permitido evaluar las pérdidas que tiene el cuerpo por la transpiración pulmonar y cutánea. Asimismo hace consideraciones sobre el baño higiénico o baño tibio, los medios baños, los baños parciales y las abluciones cotidianas. Y todo ello para aclarar como ejerce su influencia sobre el organismo el líquido de los baños. El problema lo concreta en una pregunta: ¿Es atravesando la piel o por el simple contacto con esta "membrana"? Partiendo de la idea de Haller de que la piel absorbe el agua de los baños, y que por tanto el peso del cuerpo aumenta, pasa a rebatir esta idea a con los experimentos de Seguin que afirmaba que en ninguna circunstancia aumentamos de peso durante nuestra estancia en el agua, que mientras se está en el baño, "perdemos un poco menos que cuando estamos en el aire atmosférico" y "que está igualmente demostrado despues de veinticinco

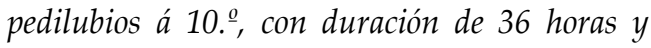
conteniendo tres onzas y tres dracmas de sublimado, que la absorción de este liquido tampoco había tenido lugar, toda vez que no se había presentado sintoma alguno de envenenamiento". Seguin repitió sus experimentos en enfermos venéreos, deduciendo que el cuerpo, lejos de aumentar de peso, disminuye en el baño, y que las "sustancias estrañas" añadidas al agua, no atraviesan la piel, sino cuando esta última presenta solución de continuidad; " $y$ que por consiguiente la cubierta cutánea no posee la facultad de absorber". Sin embargo, Cortinas opina que el problema está aún por resolver en tanto que nuevas investigaciones confirmen o no los resultados apuntados por Seguin.

El hidrólogo jerezano también se detiene a considerar el agua como medio terapéutica: "Si se bebe á la temperatura atmosférica, en mayor ó menor cantidad, mitiga la sed, disminuye el calor febril, activa las secreciones y las exhalaciones, y modifica evidentemente sus productos, como es fácil conocer por el más ligero exámen de estos líquidos, de la orina por ejemplo. No es común que se administre el agua pura. Pocos médicos la prescriben, y si la prescribiesen, no es probable que se observasen sus preceptos; tal es la energía con que las preocupaciones rechazan todo lo que es sencillo y natural. Lo más común en la práctica es, prescribirla añadiéndole algunas sustancias insignificantes, que no modifican sensiblemente sus cualidades, como la azúcar, la fécula, alguna materia extractiva, algún aceite volátil, etc.".

Reivindica el agua tibia como emética y la 
ingestión de gran cantidad de agua caliente, manteniéndose el enfermo bien tapado y en una temperatura elevada, como el medio más seguro de activar la exhalación cutánea. Recomienda el uso de las bebidas acuosas en las afecciones infamatorias de la vejiga y de la uretra. Aunque no contempla la hidroterapia como un remedio universal: "Creémosla inútil en ciertas enfermedades, tanto, como nociva en otras; así como creemos puede serle muy conveniente á las personas flojas y linfáticas, toda vez que posee la ventaja de desinfartar los tejidos por medio de sudores abundantes, y de dar tono á los diversos sistemas: la piel comprimida por el agua fría, se libra de los líquidos subyacentes; la constitución se fortifica, (...). Resumiendo, diremos, que el agua-hielo obra como astringente y es repercusiva, tónica y resolutiva; que la fría es refrigerante, calmante y emética; tibia es laxante, calmante y emética, según los casos; que la caliente es excitante, sudorífica y expectorante; y que el agua hirviendo es rubefaciente, cáustica y aun escarótica".

Otro autor que publica en la Gaceta es Pedro Ruiz Berdejo, concretamente un artículo titulado "Eclampsia. Parto prematuro artificial. Curación" (GM-QJ: I (1871), 3, pp. 62-65). Esta observación clínica ya había sido reproducida en la revista gaditana El Progreso Médico, pero el autor considera que tiene interés volverla a publicar en las páginas de la Gaceta. Esta circunstancia nos indica la relación que existió entre la redacción del periódico jerezano y $E l$ Progreso Médico, publicado en Cádiz, pero dirigido por el jerezano Juan José Cambas Gallego.

Sobre Pedro Ruiz Berdejo podemos indicar que fue bautizado en la Parroquia de San Miguel de Jerez de la Frontera el 28 de octubre de 1846, y que era hijo de Antonio Ruiz Berdejo, médico y cirujano, y de doña Josefa Benítez. De 1857 a 1863 realizó las asignaturas de la segunda enseñanza en el
Instituto Provincial de Jerez. Estudió la carrera de medicina en la Facultad de Cádiz, las asignaturas del preparatorio las realizó en el curso 1863-1864 y el primer año de carrera en el curso 1864-1865. El grado de Bachiller en Medicina y Cirugía lo obtuvo en junio de 1868 y el grado de licenciado en septiembre de 1869. El grado de doctor en septiembre de 1869 con una Memoria que lleva por título "Medicina de los Árabes" (Expediente de alumno de Pedro Ruiz Berdejo en la Facultad de Medicina; HerreraRodríguez, 1987).

Pedro Ruiz Berdejo en este caso clínico ofrece información muy interesante sobre los médicos del Hospital de Santa Isabel de Jerez, ya que todos los citados participan de una u otra manera en la resolución del caso. Cita a Francisco Revueltas como "encargado especialmente de la clínica quirúrgica", y también a otros dos "profesores" del hospital, Manuel Fontán, al que hemos dedicado un apartado anteriormente, y Francisco Hernández, del Departamento de maternidad del hospital. La historia clínica versa sobre una joven de 17 años, primeriza, embarazada de "ocho meses cumplidos", ingresada desde hacía dos meses en el hospital, que ya casi al final del embarazo tuvo repentinamente convulsiones seguidas de "estupor". El doctor Hernández le prescribió una evacuación general, que se repitió horas después, y fricciones antiespasmódicas, "y se ponían revulsivos en las extremidades". La paciente no mejoró y los accesos se repitieron cada vez con más intensidad y frecuencia, sin que cediera el estado comatoso. El doctor Revueltas diagnosticó una eclampsia y recomendó "la provocación del parto prematuro", mostrando su conformidad todos los médicos citados. Procedieron a realizar la operación los doctores Revueltas, Hernández y como ayudante el propio Ruiz Berdejo, que ofrece 
explicaciones para justificar la provocación del parto en los casos de eclampsia apoyándose en autores como Moreau, Scanzone o Dubois, "pues quizás entonces se consiga, no solo salvar la vida de la madre, sino también la del feto, que no puede resistir á los embates de convulsiones tan fuertes, y repetidas con tanta intensidad". La operación en el caso que nos ocupa se llevó a cabo realizando dilatación del cuello del útero manualmente, rotura de las membranas y utilización del fórceps. La madre superó la intervención pero "al feto se le prodigaron toda clase de auxilios indicados para estos casos, sin conseguir por ellos volverlo á la vida. La placenta fué extraída, pasando algun tiempo sin que antes ni despues hubiera hemorragia, contrayéndose el útero con regularidad".

Pedro Ruiz Berdejo ofrece algunos datos más sobre las circunstancias personales de esta joven de 17 años y algunas reflexiones sobre las posibles causas que motivan la eclampsia. En cuanto a la joven indica que su concepción es "hija de un momento de extravio", y que "quiso ocultarla á todos, y pretestando un viaje, se refugió en el Hospital, donde estuvo aislada los dos meses anteriores á la invasión del mal; durante ellos nadie la había visto, y como nada en ella se presentó, ningún profesor tuvo ocasión de observarla...". Ruiz Berdejo plantea la siguiente pregunta: " $i A$ quépuede, pues, atribuirse la eclampsia en el caso que nos ocupa?". Su respuesta es especulativa, pero sirve para entender lo que pensaban los médicos sobre la eclampsia: "¿Será á la irritación de los nervios uterinos que existiendo en todas las embarazadas, se aumentó en esta, por la compresión ejercida tanto tiempo sobre la pared del vientre, y que irritando á su vez los de la médula, provocase esta acción refleja que se manifestó por la contracción de los músculos motores? ¿O, fueron provocadas las convulsiones por el estado de su acción, el recuerdo de su falta, los remordimientos á que esta diera lugar, viendo perdida la tranquilidad y el contento en las personas de su familia, sabedoras de ella, y la soledad en que se hallaba, por la separación forzosa de su padre? ¿Fue, quizás, un padecimiento hereditario, lo que se observó en esta forma, con manifestación distinta que en su madre? Mucho pudo influir la soledad la tristeza, causas morales sin duda. Pero, ¿a qué fijarse en ellas, cuando las físicas existen?". La utilización por la joven de una "fuerte faja" antes de abandonar su casa, "que comprimiéndola hacia desaparecer el vientre á todas las miradas". La madre de la joven también utilizó el fajamiento en todos sus partos, "muriendo á consecuencia de uno". Finalmente Ruiz Berdejo apunta: "La fuerte compresion sostenida por tantos meses, puede dar lugar, no solo al aumento de irritación de los nervios uterinos, que irritan á su vez los de la médula, sino que ha de producir necesariamente congestiones pasivas en esta, ejercida durante un largo periodo, y precisamente en el más se aviva la circulacion de sus órganos, y congestiones que efectuadas ya en la médula, ejercerán sobre ella una segunda compresion que habrán de reflejarse al cerebro. No por esto deben desatenderse los antecedentes de su madre, que manifiestan una disposición nerviosa hereditaria...".

Como se puede apreciar el artículo tiene sumo interés desde el punto de vista etiológico y clínico, pero también sobre las circunstancias sociales, familiares, morales que llevaban a una mujer a ocultar su embarazo en una maternidad en la segunda mitad del siglo XIX, sobre este particular hemos reflexionado hace unos años en un artículo dedicado a la casa de maternidad de Cádiz a finales de la citada centuria (Herrera-Rodríguez, 1999).

También publica en la Gaceta Leonardo Navas Román, concretamente su discurso leído en el claustro de la Facultad de Medicina de Cádiz en el acto de recibir la investidura de doctor en 1872, un trabajo 
que lleva por título "Determinar ó señalar los inconvenientes y perjuicios que resultan á los individuos, la familia y la sociedad, por las faltas y engaños en el cumplimiento de las funciones de la generación" (GM-QJ: I (1872), 8, p. 220; I (1872), 10, pp. 266-268; I (1872), 11, pp. 289292; I (1872), 12, pp. 305-308). Una obra a la que ya prestamos atención en nuestro trabajo sobre las tesis doctorales defendidas en la Facultad de Medicina de Cádiz en la segunda mitad del siglo XIX (HerreraRodríguez, 1987).

Sobre Leonardo Navas y Román podemos indicar que nació en Sanlúcar de Barrameda el 6 de febrero de 1840, hijo de Leonardo Navas y María del Rosario Román. Realizó la carrera de medicina en la Facultad de Cádiz, en la que comenzó sus estudios en el curso 1858-1859. En 1862 obtuvo el grado de Bachiller en Medicina y Cirugía; dos años después, en 1864, alcanzó el grado de licenciado, y se doctoró también en la Facultad gaditana en enero de 1872. En su expediente de alumno en la Facultad de Medicina se puede localizar un ejemplar impreso de su Memoria de doctorado, que como podemos apreciar también publicó en las páginas de la Gaceta (Cf. Navas Román, 1872; Expediente de alumno de Leonardo Navas Román en la Facultad de Medicina de Cádiz; Herrera-Rodríguez, 1987). En este discurso Navas se muestra contrario a los "matrimonios tardíos" ya que las consecuencias "son, hijos endebles, valetudinarios y enfermizos, mientras una série no interrumpida de males aqueja á sus infelices procreadores; desarrollo incompleto de la talla $y$ robustez precisa; marchitez de las facultades intelectuales; vida laboriosa; vejez prematura; $y$ en las mujeres, con especialidad, disposición al aborto. Análogos inconvenientes acarrean los matrimonios entre marido viejo y mujer de poca edad, como suelen ser estériles é infecundos los adquiridos en condiciones opuestas". Asimismo se muestra contrario a los matrimonios entre consanguíneos, "pues las escasez de la prole, los vicios en su organización física y moral, se perpetúan en las familias". Y también expone su crítica a los matrimonios "entre individuos enfermos ó mal constituidos, son, por último, la causa principal de contraer otros males, entre ellos los sifilíticos, fuente fecunda de la degradación física de nuestra especie, así como de que la mujer destruya su vida y la del feto en partos imposibles ó laboriosos". En su texto realiza una reflexión sobre los sacerdotes y las monjas. Dice así: "Enhorabuena que los hombres destinados al sosten de la Religion necesiten emanciparse de las influencias terrenales para acercarse al ideal divino á que conducen la humanidad; pero interesa á la sociedad y la Religion que en ellos, así como en las vírgenes destinadas al cláustro, haya equilibrio entre la continencia física y la grandeza moral, para que las tentaciones de unos, las luchas de otros, los atentados á la personalidad propia, no vengan á aumentar las víctimas de las continencias amorosas, ó convertir en tristes manicomios los asilos de la piedad".

Leonardo de Navas se muestra contrario a la prostitución, dedica también algunas reflexiones a los problemas anatómicos, fisiológicos y patológicos, y finalmente párrafos a la influencia "de la disposición hereditaria en lo que atañe á la funcion generadora". Su opinión es que se heredan el carácter, la inteligencia, los sentimientos y la propensión al crimen. El siguiente párrafo resume sus ideas de la cuestión: "Trasmítese la sífilis del padre á la madre, y vice-versa; de la nodriza al niño, y de este á aquella; al producto de la concepción en el seno materno por la influencia del padre y de la madre, y á esta tambien por la influencia de la critatura que aun no ha espulsado; del sémen al óbulo, en el momento de la concepcion, por el intermedio del padre; por el de la madre al obulo, en el de su formacion, antes del embarazo, ó por inoculación, una vez 
adelantado este; otras veces es el feto el agente conductor, sin contagio prévio á la aproximación sexual, siendo espulsado con síntomas sifilíticos, ó desarrollándose estos consecutivamente en él. Herédanse muchas veces las escrófulas; no pocas, la gota y el reumatismo; los tubérculos, ó disposicion á la tisis pulmonar; las enfermedades de la piel; el cáncer; las afecciones nerviosas, y hasta la enagenacion mental".

En las páginas de la Gaceta aparece también un interesante y extenso artículo de José Antonio Reynés titulado "Del estado presente de la medicina y sus tendencias para el porvenir" (GM-QJ: I (1872), 12, pp. 293-300). En la propia Gaceta comprobamos el dato de que el doctor Reynés trabajaba en el hospital de San Felipe y Santiago, y que colaboró en los "Anales de la Real Academia de ciencias médicas, físicas y naturales" de La Habana (GM-QJ: I (1872), 8, p. 216). El artículo de Reynés es un trabajo bien escrito, que reconoce las observaciones de los grandes autores del pasado como Hipócrates, Baglivi, Syndenham, Stoll, Boerhaave, Haller, etc: "Los grandes hombres de la antigüedad, ha dicho el canciller Bacon, son unos gigantes sobre cuyos hombros se han empinado unos pigmeos, los que de esta manera alcanzan á ver más lejos". Reynés repasa la medicina del siglo XIX partiendo del sistema médico de Broussais, que "destruía de una plumada toda la patología de las fiebres que reducía á una gastro-enteritis", colocando en la cúspide de su doctrina "la propiedad más característica del tejido vivo, la irritabilidad", y en la terapéutica se apoyaba en "las emisiones sanguíneas". A partir de la decadencia del sistema de Broussais, Reynés apoya en su artículo los adelantos de la Química con figuras como Lavoisier, en la Fisiología con Claude Bernard, el tratado de anatomía general de Bichat, el microscopio y la teoría celular, los trabajos de Virchow, sin olvidarse de los trabajos de Brown Sequard, Schiff, Mategazza, Traube, etc., y en lo referido a la terapéutica resalta que "por medio del análisis químico se extraen los principios activos de las sustancias medicinales y se facilita su acción al mismo tiempo que se le da mayor energía". Destaca los estudios de la eserina por Vee, Eben, Watson, Leben y Laborde, o los trabajos de Richardson sobre los efectos fisiológicos de los bromuros orgánicos y del hidrato de cloral, o los de Harley sobre la cicuta, la conicina, la belladona, la atropina y el beleño, "haciendo ensayos en animales y determinando sus afectos en todos los aparato orgánicos, sus antagonismos y sus vías de eliminacion". Asimismo destaca los estudios que "Althauss, Ciniselli, Becquerel, Onimus, Legrus, Neftel, Fleury y otros obtienen con la electricidad y el agua aplicadas a la curación de enfermedades que habian sido consideradas como incurables". Reynés realiza en las páginas de la Gaceta Médico-Quirúrgica Jerezana un firme alegato de la medicina clínica, pero también de la medicina experimental cuyo fundamento es el laboratorio y el estudio de la fisiología animal, así como del análisis químico $y$ sus repercusiones en la terapéutica. En las páginas de la Gaceta, pues, en 1872, observamos que tienen cabida reflexiones sobre la medicina experimental y de laboratorio, que se irá consolidando en las décadas siguientes. Curiosamente, en este último número de la revista, en su primera época, Revueltas Carrillo sacrifica un artículo suyo para dar entrada al de José Antonio Reynés. Dice así: "Notable y mucho el discurso del que á continuación copiamos los principales párrafos y casi en totalidad, es casi seguro que habrán de leerlo con gusto nuestros suscritores, por lo cual retiramos el artículo de «Resección y amputaciones>, dejándolo para el número inmediato" (GM-QJ: I (1872), 12, p. 293).

La dirección de la Gaceta Médico-Quirúrgica Jerezana también demuestra su apertura a la medicina que se está fraguando en el extranjero, al encargar al Dr. Gerard, de 
Breuning (Austria), un artículo titulado "Comunicaciones médicas alemanas" (GM-QJ: I (1872), 10, pp. 248-253). Artículo en el que el Dr. Gerard ofrece noticias sobre los trabajos de Luis Martini, de Augsburgo, sobre los infartos y endurecimientos de la matriz, en el cual se recogen las principales ideas etiológicas, clínicas y terapéuticas de este médico, que el propio Gerard visitó para conocer su experiencia médica personalmente, y su uso del cloruro de oro, cuya prescripción era muy debatida en la época, resumiéndolo así el Dr. Gerard: “ $A$ pesar de estas preocupaciones contra el medicamento motivo de este artículo, el Dr. Martini, (...), recomienda su uso, asegurando que no obra como anti-histérico, pero que seguramente combatirá las inflamaciones crónicas de las partes sexuales de las mujeres y sus consecuencias".

No queremos dejar pasar, ahora que comentamos aspectos terapéuticos que aparecen en la Gaceta, la existencia de cuatro páginas dedicadas de forma anónima al cundurango, calificado como "exótico vejetal" (GM-QJ: I (1872), 6, p. 155; I (1872), 7, p. 186; I (1872), 8, pp. 216-217). La redacción de la Gaceta se hace eco del debate sobre el uso del cundurango como un agente eficaz para la curación del cáncer. Se da cuenta de que los químicos lo han preparado "con un hidro-alcoholato llamado por los franceses cunduranguina, con el polvo de la corteza y con el jarabe". En Quito lo consideran una panacea, mientras que en Estados Unidos, y en España, "muchos y notables profesores califican su uso de extravagancia y superchería". Se da noticia de que en el Hospital de Santa Isabel de Jerez se está "esperimentando en una mujer que se encuentra en el Hospital afecta de un cáncer uterino; no hemos querido formarnos ilusiones engañosas, antes bien, abrigábamos alguna desconfianza en sus efectos; pero hasta el dia hemos venido encontrando un gran alivio tanto local como general en nuestra enferma. Sin embargo, a lo hemos dicho, no queremos dejarnos seducir por una mejoría que podrá ser pasagera...". La prescripción que se sigue en el hospital jerezano es la indicada por el Dr. Bouison: "Tomar una cucharada de café de la cunduranguina un cuarto de hora antes de cada comida quedando en libertad de aumentar la dosis; rociar la superficie ulcerosa con el polvo de la corteza dos ó tres veces cada dia despues de haberla lavado antes con agua tibia; prohibiendo al paciente el uso de vinos, licores, tabaco, alimentos cargados de especies, poca leche, etc.; $y$ si el enfermo, despues de algunos días de tratamiento, esperimenta un malestar general, se suspende momentáneamente toda preparacion con base de cundurango, á escepcion del polvo sobre la úlcera". Poco después de esta noticia, la experiencia clínica en el hospital se amplía a tres pacientes con la misma enfermedad, "en todas ha habido reconstitucion de su pobre economía, buen apetito, mejorando notable y rápidamente el ejercicio de todas las funciones, antes entorpecidas y debilitadas: en cuanto á su efecto curativo radical, nada podemos asegurar todavía, á pesar de venirlo ensayando hace cuatro meses, desconfiando, sin embargo, mucho de sus virtudes anti-cancerosas, pues los efectos obtenidos localmente no corresponden á fecha tan larga de su uso; pero lo que sí podemos afirmar es, que al mismo tiempo que detiene admirablemente las hemorragias cancerosas, tiene una ventaja para calmar los dolores especiales de aquella enfermedad, siendo su eficacia superior á la del ópio, que llega á ser inútil, cuando se ha establecido la tolerancia en el sistema nerviososo...". En los breves informes que se ofrecen en la revista jerezana también se expone la experiencia de otros clínicos; negativos, como el que expone Reynés sobre el uso del cocimiento del cundurango en un paciente con cáncer epitelial de la lengua del hospital de San Felipe y Santiago; y positivos, como los expresados por los 
doctores Gutiérrez y Mestre en una paciente con "cáncer de pecho".

Para concluir con este apartado debemos incluir dos publicaciones más de la Gaceta: la primera, firmada por el "Dr. Cambas" (GMQJ: I (1872), 7, pp. 187-188). Este Dr. Cambas es Juan José Cambas Gallego, médico jerezano, profesor clínico de la Facultad de Medicina de Cádiz y director de El Progreso Médico, sobre el que aportamos su biografía en otro trabajo (Herrera-Rodríguez, 1994). El artículo que firma es una breve nota titulada "Solemnidad Académica", en la que se realiza una crónica de la toma de posesión de su cargo del nuevo Decano de la Facultad de Medicina de Cádiz, el Dr. Francisco Flores Arenas, "teniendo lugar dicho acto bajo la presidencia del Ilmo. Sr. Rector D. José María de Álava, con verdadera é imponente solemnidad ante Cláustro pleno, en el que se hallaba el de la Facultad libre de Farmacia". La segunda publicación a la que hacemos referencia, a la cual ya hemos aludido al comentar los trabajos de Revueltas Carrillo y de Fontán, es la página desplegable que aparece al final del volumen con los 12 números de la Gaceta que comentamos, que también está firmada por Francisco J. Hernández, y que recoge la estadística del Hospital General de Santa Isabel de Jerez de la Frontera en 1871 (GM-QJ: I (1872), 12. Página desplegable).

Tampoco podemos olvidar que Francisco de Barea y Francisco G. Reguera, respectivamente, publican en varios números de la revista las estadísticas mensuales del número de acogidos en el Hospicio Provincial y de los albergados en la
Casa de Expósitos en Jerez de la Frontera. Asimismo, la Gaceta ofrece los datos facilitados por los "Jueces Municipales" mensualmente del estado de defunciones y nacimientos, también son de gran interés los informes sobre el estado sanitario en la ciudad, aspectos que quedan recogidos en el índice de la revista que presentamos en este trabajo. Todo lo apuntado convierte a la Gaceta en una fuente documental de notable interés para profundizar no solo en la historia del Hospital de Santa Isabel y de las figuras médicas o de los temas tratados, sino también de las instituciones asistenciales y de la sanidad jerezana.

\subsection{La enseñanza clínica: los alumnos de medicina que publicaron en la revista}

Uno de los aspectos que ha llamado nuestra atención en el estudio de la Gaceta Médico-Quirúrgica Jerezana ha sido la actividad docente en la formación médica de alumnos, que durante los años de publicación de la revista realizaban prácticas en el Hospital de Santa Isabel. No olvidemos que el director de la revista, Francisco Revueltas, era responsable del departamento quirúrgico del citado hospital, y por lo que se puede comprobar ofreció las páginas de la misma a alumnos que en esos años cursaban la carrera en la Facultad de Medicina de Cádiz, para que redactaran artículos con las historias clínicas de los pacientes que visitaban en el hospital jerezano. 
TABLA 2: Alumnos de medicina, número de artículos que publicaron y número de páginas

\begin{tabular}{|c|c|c|}
\hline $\begin{array}{l}\text { NOMBRE DEL “ALUMNO } \\
\text { OBSERVADOR" }\end{array}$ & $\begin{array}{l}\text { NUMERO DE } \\
\text { ARTÍCULOS } \\
\text { PUBLICADOS }\end{array}$ & $\begin{array}{c}\text { NUMERO DE } \\
\text { PÁGINAS EN LA } \\
\text { REVISTA }\end{array}$ \\
\hline BERNARDO MARTÍNEZ (ÁLVAREZ) & 6 & 24 \\
\hline MANUEl BALBÁS (MARTíN) & $\begin{array}{l}5 \text { ( } 2 \text { como alumno y } 3 \\
\text { como licenciado) }\end{array}$ & $\begin{array}{l}36 \text { (12 como alumno y } \\
24 \text { como licenciado) }\end{array}$ \\
\hline José A. Benítez Navarro & 2 & 9 \\
\hline FranCisco TERÁN (SALGUERO) & 2 & 13 \\
\hline EDUARDO SOLÍs (BAZÁN) & 1 & 10 \\
\hline ANTONIO DE GRACIA (RoDRÍGUEZ) & 1 & 5 \\
\hline
\end{tabular}

FUENTE: Gaceta Médico-Quirúrgica Jerezana (1871-1872).

Entre paréntesis el segundo apellido, tomado de sus expedientes académicos en la Facultad de Medicina de Cádiz, ya que normalmente firmaban los artículos solamente con el primer apellido

Hemos comprobado que estos alumnos, que se citan en la tabla 2, en esos años estaban matriculados en la Facultad gaditana, y por alguna razón de cercanía o de afinidad con Francisco Revueltas y con Manuel Fontán realizaban las prácticas en el Hospital de Santa Isabel, aunque de esta circunstancia no hemos encontrado consignación alguna en forma de certificados de asistencia al hospital firmados por Revueltas o por Fontán en los expedientes académicos de estos alumnos, de los cuales damos constancia en el apartado de fuentes documentales ya que nos han ofrecido datos de sus biografías académicas en lo que se refiere a sus matrículas y estudios en la Facultad de Medicina de Cádiz. Desconocemos si durante el reinado de Isabel II en el hospital jerezano hubo alumnos realizando prácticas clínicas en los departamentos de medicina, cirugía o en la sección de maternidad, será este un tema que habrá que intentar aclarar en el futuro, al igual que habrá que estudiarlo en el período de la Restauración; pero como podemos apreciar en estos años, 1871 y 1872, sí se desplegó esta actividad docente, seguramente voluntaria e incentivada por la libertad de enseñanza, en la que tanto creía Francisco Revueltas, que fue propiciada durante el "sexenio democrático" (Herrera-Rodríguez, 1986, 1989 y 1992-1993).

El primero de estos alumnos, según observamos en la tabla 2, es Bernardo Martínez Álvarez. Nació en Jerez de la Frontera el 20 de abril de 1850. Obtuvo el título de Bachiller en Artes en el Instituto de Jerez en septiembre de 1866. Una vez aprobado el preparatorio de Medicina, en septiembre de 1867, solicitó matrícula en la Facultad gaditana en primer curso de la carrera. Si revisamos su expediente la mayor parte de las asignaturas las realizó en la “enseñanza oficial", pero en 1871-1872 se matriculó de Clínica Médica y Clínica Quirúrgica en la "enseñanza libre". Obtuvo el grado de licenciado en junio de 1872, siendo uno de los miembros del tribunal que lo examinó el médico jerezano Juan José Cambas (Cf. Expediente de Bernardo Martínez Álvarez en la Facultad de Medicina de Cádiz). Comprobamos que Bernardo Martínez publicó 6 artículos en las 
páginas de la Gaceta:

- "Gangrena seca de las cuatro extremidades" (GM-QJ: I (1871), 1, pp. 17-19).

- "Fractura de las dos tibias" (GM-QJ: I (1871), 2, pp. 40-43).

- "Congestión cerebral activa. Asfasia. Curación rápida" (GM-QJ: I (1872), 6, pp. 144-147.

- "Tumor escirroso de la mama derecha..." (GM-QJ: I (1872), 7, pp. 167173).

- "Parálisis esencial con asfasia. Curación" (GM-QJ: I (1872), 8, pp. 194196).

- "Ascitis dependiente de un infarto del hígado. Complicación accidental. Curación" (GM-QJ: I (1872), 9, pp. 229231).

El último artículo de Bernardo Martínez en la revista corresponde al mes de abril de 1872, en el número 9 como acabamos de apuntar. En la revista se dio noticia, en el número de 30 de junio de 1872, que había obtenido la licenciatura de medicina, lo que da muestra del interés y valor que en el hospital jerezano en estos años se dio a la formación práctica de alumnos de medicina: "Don Bernardo Martínez y Álvarez, nuestro compañero de redaccion, lo es ya en el ejercicio profesional. Despues de unos brillantes exámenes en la Facultad de Medicina y Cirugía de Cádiz, consiguió el título de Licenciado en el mes de Junio último. Damos la enhorabuena al nuevo y joven Profesor, deseándole vivamente fortuna en la práctica, y que alcance en ella el lugar á que por sus conocimientos poco comunes, bondadoso carácter y accidentes distinguidos, tiene indisputable derecho; esperando no olvide el Profesor seguir con sus escritos honrando esta publicación, como hizo hasta ahora el estudiante" (GM-QJ: I (1872), 11, p. 289).

A continuación dos nombres que pueden prestarse a confusión: "Manuel Sánchez Balbás" y "Manuel Balbás". El estudio detallado de la revista nos permite confirmar que la firma Manuel Sánchez Balbás es errónea al pie de uno de los artículos de la revista, ya que en el índice de la misma se rectifica y se atribuye dos artículos de la misma temática, que posteriormente citaremos, a "Manuel Balbás". De hecho nuestras pesquisas buscando un expediente de alumno en la Facultad de Medicina de Cádiz de Manuel Sánchez Balbás no han dado fruto, mientras que sí ha aparecido el de "Manuel Balbás Martín". Efectivamente, Manuel Balbás Martín nació en Jerez de la Frontera el 6 de octubre de 1845. Obtuvo el título de Bachiller en Artes en el Instituto de Jerez en junio de 1867, y se matriculó en primer año de la carrera de medicina en Cádiz en el curso 1867-1868. Obtuvo el grado de licenciado en septiembre de 1871. Estudiando detenidamente su expediente académico se puede observar que algunas asignaturas de la carrera las hizo en la "enseñanza oficial" mientras que otras las hizo en la "enseñanza libre" (Cf. expediente académico de Manuel Balbás Martín en la Facultad de Medicina de Cádiz). Manuel Balbás, como acabamos de apuntar, obtuvo la licenciatura en septiembre de 1871, de ahí que en algunos artículos previos publicados en la revista aparezca como "alumno observador" mientras que en otros firma ya como licenciado, para no disgregar la información ofrecemos la cita de los artículos de este autor en este apartado, ya que queremos hacer especial énfasis en que tuvo formación clínica práctica como alumno en el Hospital de Santa Isabel de Jerez de la Frontera. Sus artículos en la revista son los siguientes:

- "Laringitis pseudomembranosa: 


\section{Cultura de los Cuidados}

Traqueotomía (GM-QJ: I (1871), 1, pp. 12-17 (Consta como alumno).

- "Laringitis pseudomembranosa: Traqueotomía. Curación (GM-QJ: I (1872), 11, pp. 272-279) (Consta como licenciado).

- "Necrosis de la tibia. Resección diafisaria parcial de dicho hueso" (GMQJ: I (1871), 2, pp. 33-38) (Consta como alumno).

- "Herida por arma de fuego, interesando el vértice del pulmón izquierdo. Neumonía traumática. Curación" (GM-QJ: I (1871), 4, pp. 8489) (Consta como licenciado).

- "Hemorragia uterina. Parto prematuro artificial. Muerte" (GM-QJ: I (1872), 6, pp. 129-138) (Consta como licenciado).

Otro "alumno observador" que publicó en la Gaceta fue José Antonio Benítez Navarro. Nació el 23 de junio de 1847 y fue bautizado el mismo día en la Iglesia Parroquial de San Miguel de Jerez de la Frontera. Obtuvo el grado de Bachiller en Artes en el Instituto de Jerez en junio de 1865. Se matriculó en primer año de carrera en la Facultad de Medicina de Cádiz en el curso 1869-1870 y alcanzó el grado de licenciado en 1873. Igualmente que en casos anteriores observamos que a lo largo de la carrera alternó la matrícula en la "enseñanza oficial" y en la "enseñanza libre" (Cf. expediente académico de José A. Benítez Navarro en la Facultad de Medicina de Cádiz). Benítez Navarro publicó dos artículos en la Gaceta Médico-Quirúrgica Jerezana (Cf. Soto-Villalba, 2015):

- -"Litotomía. Proceder bilateral de Dupuytren. Curación" (GM-QJ: I (1871), 5, pp. 113-117.

- -“Catarro vexical crónico. Estrecheces de la uretra. Operación. Completa curación" (GM-QJ: I (1872), 7, pp. 174-
177).

Francisco Terán Salguero publicó en la revista dos artículos. De él podemos apuntar que era natural de Jerez de la Frontera y que debió nacer en torno a 1850. Estudió medicina en la Facultad gaditana alternando en las asignaturas la "enseñanza oficial" y la "enseñanza libre". Comenzó la carrera en el curso 1869-1870 y obtuvo el grado de licenciado en octubre de 1872 . Se presentó al grado de doctor en septiembre de 1874 (Cf. el expediente de Francisco Terán Salguero en la Facultad de Medicina de Cádiz). Los artículos publicados en la revista por este alumno son los siguientes:

- -"Necrosis de la tibia. Resección de la totalidad de dicho hueso" (GM-QJ: I (1871), 5, pp. 117-123).

- -"Carcinomas tratados por la pomada arsenical. Curaciones" (GM-QJ: I (1872), 9, pp. 231-236).

Eduardo Solís Bazán nació en Jerez de la Frontera el 23 de septiembre de 1848. Realizó los ejercicios de Bachiller en Artes en el Instituto de Jerez en junio de 1868. Comenzó la carrera en la Facultad de Medicina de Cádiz en el curso 1868-1869 y alcanzó la licenciatura en junio de 1872 (Cf. el expediente de Eduardo Solís Bazán en la Facultad de Medicina de Cádiz). Publicó un artículo en la revista jerezana titulado "Herida contusa con fractura del antebrazo. Amputación" (GM-QJ: I (1872), 8, pp. 197206).

Antonio José de Gracia Rodríguez era natural de Tarifa (provincia de Cádiz). Nació el 10 de noviembre de 1841. Su padre Antonio de Gracia era "corchero" y trabajaba en el campo. Se examinó del grado de Bachiller en Artes en agosto de 1869 en el Instituto de Segunda Enseñanza de Cádiz. Estudió en la Facultad de Medicina de 
Cádiz, matriculándose primero en la carrera de Facultativo de Segunda clase. Realizó la carrera de medicina, alternando también la "enseñanza oficial" y la "enseñanza libre", consiguiendo el grado de licenciado en junio de 1872 (Cf. el expediente de Antonio de Gracia Rodríguez en la Facultad de Medicina de Cádiz). Publicó un artículo en la revista: "Inflamación del escroto. Terminación por gangrena. Eliminación completa de aquel. Curación" (GM-QJ: I (1872), 10, pp. 253-257) (Cf. Soto-Villalba, 2015).

\section{Epílogo}

Como se ha podido apreciar en el apartado anterior fueron varios los estudiantes que volcaron en la revista jerezana su aprendizaje clínico como "alumnos observadores", ocupando sus publicaciones en la misma varias decenas de páginas. En este sentido se debe reconocer la labor docente y la incentivación que llevó a cabo en el Hospital de Santa Isabel de Jerez de la Frontera el director de la revista, Francisco Revueltas, que sin duda sembró inquietudes en los jóvenes que lo rodeaban. En este sentido también se debe tener en cuenta el nombre del Manuel Fontán Crespo, médico del hospital y redactor de la Gaceta.

El afán docente del Dr. Revueltas queda patente, pues, en esta revista; aunque esta faceta ya la constatamos hace algunos años cuando comprobamos que aprovechando el decreto de 21 de octubre de 1868, de Manuel Ruiz Zorrilla, que liberalizó la enseñanza en todos sus grados y clases, Revueltas formó en el Hospital de Santa Isabel de Jerez a un practicante y a tres matronas, que con su certificado de haber realizado prácticas con él se examinaron para obtener estos títulos en la Facultad de Medicina de Cádiz. Merece la pena dejar aquí consignados sus nombres ya que completan el perfil docente de este médico jerezano al menos en los años del "sexenio democrático", aunque en futuras investigaciones habrá que constatar si esta labor la siguió realizando en el hospital jerezano hasta la fecha de su temprana muerte. Nos referimos a Vicente Marín González, nacido en Ronda (Málaga) en noviembre de 1849 , que realizó sus estudios de practicante con Revueltas y se revalidó en la Facultad gaditana en septiembre de 1871. Inés de Peña y Vargas, de Jerez de la Frontera, estudió con Revueltas en el Hospital de Santa Isabel de Jerez realizando su examen de reválida de matrona en la Facultad de Medicina de Cádiz en 1869. Asimismo María del Carmen Molinillo Marín, de Setenil de las Bodegas (Cádiz) y vecina de Jerez, estudió con Revueltas en el hospital jerezano y obtuvo su título de matrona en la Facultad gaditana en 1871 (Cf. los expedientes de alumnos, en la Facultad de Medicina de Cádiz, de Vicente Marín González, Inés de Peña y Vargas y María del Carmen Molinillo Marín; HerreraRodríguez, 1986, 1989 y 1992-1993). No descartamos que en el futuro puedan aparecer algunos nombres más de practicantes, matronas y de médicos que recibieran enseñanzas del médico jerezano.

Un examen detallado de notas y noticias que aparecen en la Gaceta Médico-Quirúrgica Jerezana nos hace comprender que su director y fundador, Francisco Revueltas, puso de manifiesto sus creencias en los beneficios que puede reportar al país la libertad de enseñanza. He aquí un ejemplo de una nota, sin firma, aparecida en la revista, y que probablemente fue redactada por su director: "Partidarios de la libertad de enseñanza en todas sus manifestaciones, porque de ella esperamos que la luz de las ciencias se difunda libre de preocupaciones, sentimos un verdadero placer siempre que tenemos noticia de 
que un nuevo establecimiento, debido á la iniciativa individual, llama á sus aulas á la juventud española que, ávida de saber, no le ha sido posible en otras épocas satisfacer sus deseos, no solo por las trabas enojosas que los gobiernos reaccionarios imponían á la enseñanza, sino por la escasez de establecimientos. Por nuestra parte, creemos contribuir á la realizacion de la libre enseñanza, dando publicidad á todos los programas de las academias ó escuelas particulares que se nos remitan". En esta línea, por ejemplo, la revista ofrece información de la Academia de Farmacia, instalada en Madrid, en la calle Tudescos 39, en la que se ofrecen lecciones teóricas y prácticas de Física, Química e Historia Natural, o de la inauguración de la Facultad libre de Farmacia establecida en Cádiz "en el mismo local que ocupa la oficial de Medicina" (Cf. GMQJ: I (1871), 4, pp. 96-97). Igualmente se recibe con entusiasmo en las páginas de la revista la organización de un Congreso escolar, nota sin firma en la que se aprovecha para realizar una crítica a los detractores de la libertad de enseñanza. Dice así: "La juventud estudiosa de España, esa juventud esencialmente liberal, que tan preciosas y fuertes columnas ofrece al edificio moderno, ha correspondido al llamamiento de sus hermanos para formar un Congreso escolar, donde entre todos se discuta y apruebe el modo de vigilar por la clase, atendiendo con especialidad al adelanto de sus amadas ciencias, tan descuidadas hoy, en general, por los que en primer lugar debian patrocinarlas y rendirle culto. Aprendan ahí los tiranos de la libertad, de la enseñanza particularmente, y vean los resultados de ella los que creían que bajo su influjo pudiera cerrarse el sagrado templo de la ciencia. Tome ejemplo los apóstoles del retroceso, de esa juventud que con facultades ámplias para el descuido, vela, sin embargo, por lo que ellos tan malamente trataron con sus prácticas rutinarias. Deseosos nosotros de que la libertad sea un hecho, y gozosos ante sus desenvolvimiento general y particularmente con el iniciado, nos adherimos á ese gran pensamiento, ya hoy puesto en práctica, y tanto más preciso, cuanto que las últimas circulares del ministerio de Fomento dicen bien claro, que se piensa la libertad de enseñanza. Con este motivo, tenemos el gusto de ofrecer las páginas de esta publicacion á la juventud escolar" (GM-QJ: I (1872), 10, p. 264).

No se puede pasar por alto una noticia sin firma, que seguramente también fue redactada por Francisco Revueltas, sobre los muertos en los campos de batalla y en los hospitales; después de ofrecer las terribles estadísticas, siguen unas frases que pueden ayudar a entender el perfil humano e ideológico de este médico jerezano: "Resultado: una corona y un manto imperial (...) ¡Cuánta sangre! ¡cuántas lágrimas! ¡cuántos dolores!" (GM-QJ: I (1872), 7, p. 188).

$\mathrm{Al}$ igual que se ofrecen noticias sobre las cifras de muertos en las guerras, la libertad de enseñanza, congresos, publicaciones, convocatorias de premios, por ejemplo de la Academia de Medicina de Madrid, también aparecen convocatorias de matrícula de la Escuela de Medicina y Cirugía de Sevilla, con su cuadro de profesores (GM-QJ: I (1871), 1, pp. 23-24). Observamos que uno de estos profesores de la escuela médica sevillana, el médico portuense Federico Rubio y Galí, colaboró en las páginas de la revista como hemos dejado consignado en este artículo, y que Adolfo de la Rosa, oftalmólogo, y catedrático de la disciplina en la citada escuela sevillana, operó a tres pacientes en 1871 en el Hospital de Santa Isabel de Jerez; concretamente operó a dos pacientes de cataratas, uno por el método de colgajo simple y queratotomía superior, y al otro por el proceder lineal combinado de Graefe. Al tercer paciente se le realizó la enucleación de un ojo, como tratamiento de una ambliopía simpática, por el proceder de 
Bonnet de Lyon, "modificado por el operador". Ofreció también una conferencia sobre las técnicas quirúrgicas empleadas (GM-QJ: I (1871), 4, p. 94).

Asimismo, en las páginas de la Gaceta, también se recoge la noticia de la visita al hospital del Dr. Melchor Sánchez Toca (1806-1880), que elogió las condiciones higiénicas del mismo, visitando tanto la clínica médica dirigida por el doctor Manuel Fontán, y la clínica quirúrgica donde junto al doctor "Revueltas Carrillo" estudió el caso de un paciente que padecía un tumor aneurismático en el tercio inferior del muslo izquierdo. En el momento en que Sánchez de Toca visita el hospital jerezano estaba ya retirado de la práctica médica en la que había destacado principalmente como cirujano y obstetra, profesor en Madrid, cirujano de Palacio, presidente de la Academia de Medicina y por sus publicaciones en "El Siglo Médico" y en la "Revista de Medicina y Cirugía Prácticas" (Matilla, 1982; Granjel, 1986). Por esta crónica de la visita de Sánchez de Toca sabemos que en esos momentos la Superiora de las Hijas de la Caridad en el hospital jerezano era sor Tomasa Ochoa (GM-QJ: I (1872), 8, pp. 214-216).

Encontramos noticias en la revista sobre la junta provincial de la Asamblea MédicoFarmacéutica Española, y más concretamente la constitución de la Junta de Jerez de la Frontera, sobre ésta última se ofrece noticia detallada de la reunión de médicos y farmacéuticos celebrada en Jerez el 24 de agosto de 1871, constituyendo una mesa interina integrada por los médicos Manuel Ruiz de la Rabia y Francisco Revueltas, elogiando la iniciativa que a nivel nacional había tenido el médico jerezano Juan José Cambas Gallego. A esta reunión acudieron Manuel Ruiz de la Rabia, Francisco Revueltas, Antonio Jiménez,
Benito Rivero, José Heredia, Domingo Grondona, Joaquín Ruiz Acosta (farmacéutico), Joaquín Martín (farmacéutico), Antonio Juille, Antonio Márquez, Salvador del Blanco, Francisco Javier Hernández, Francisco de P. Barea, Juan Fontán, Vitalio Coloma, José Montaut, Cayetano Pérez y Francisco Solís. Benito Rivero tomó la palabra, para manifestar que los facultativos Joaquín Guarro, Manuel Fontán y el Farmacéutico Juan Ortega y Daporto, a quienes representaba, y él mismo, pedían a sus compañeros, después de manifestar su completa adhesión al pensamiento, no se les confiara cargo alguno, que su edad y constantes ocupaciones les impediría desempeñar. También se adhirió, desde Chiclana, el facultativo Juan Cortinas, médico de baños en la citada localidad. Finalmente se eligieron los cargos de Presidente, Tesorero y Secretario, resultando elegidos respectivamente Manuel de la Rabia, Joaquín Martín y Francisco Revueltas (Cf. I (1871), 2, pp. 48-49; I (1871), 4, pp. 95-96).

Nos ha llamado la atención que en la revista se reproduce un artículo publicado en The Lancet, de Londres, que lleva por título "La profesión en España" en el que se afirma literalmente: "A pesar de las universidades con que España cuenta, y todas ó su mayor parte con facultad de medicina, ha sido el país de Europa que menos contribuyó á la ciencia médica y al arte de curar. No está aún muy lejana la época, en que la anatomía era imposible fuese estudiada en el cuerpo humano, porque la Iglesia se oponía á ello, teniendo que hacerlo en láminas ó cuerpos de cera. Los pocos médicos verdaderamente perfectos que ha habido en la Península, estudiaron en Montpeller (sic) ó en París, y los tratados de medicina ó cirugía, que merecen la pena de ser leídos, son compilaciones ó traducciones hechas de aquel idioma: -el alemán y el inglés parecen ser idiomas inaccesibles á los 
españoles- y la práctica que se hace en los hospitales es demasiado pobre para formar una escuela de educación médica". Además de las críticas a las deficiencias hospitalarias y al predominio en la dirección eclesiástica de los mismos, también se hace referencia al curanderismo, a los barberos sangradores, al charlatanismo y a la gran incidencia de la tuberculosis en ciudades como Cádiz y Barcelona, además de la alta mortalidad en todas las ciudades, "debiéndose no solo á aquella, sino á las enfermedades adquiridas, cuya higiene está en completo abandono". El articulista de The Lancet califica a España como la "hermosa dormida de la Europa". En la redacción de la Gaceta Médico-Quirúrgica Jerezana se reacciona ante este artículo con una respuesta que seguramente redactó Francisco Revueltas, en la que consigna "que solo la ignorancia completa de la historia de la Medicina puede dar lugar á que se desconozca la brillante página que á España corresponde". Se puede reconocer, afirma, algunos periodos de decadencia, pero precisamente es en Inglaterra "donde seguramente estos períodos son inmensamente mayores que los nuestros...". Uno de las principales críticas la centra en la cirugía inglesa a la que califica de "poco conservadora", señalando que España es la que "ha sostenido la bandera más humanitaria en cirujía". Sí hay, en cambio, un reconocimiento a los dardos críticos de The Lancet: "Nosotros somos los primeros en reconocer que, desde que vivimos doctrinariamente gobernados, nuestra importancia científica ha decaído extraordinariamente, llegando hasta la exajeracion ese estado bajo la privanza de monjas milagreras y frailes inmundos; pero no consideramos noble proceder hacer de estos periodos transitorios, una arrojadiza contra un pueblo que tiene que salir triunfante siempre que se le compara con otro cualquiera, en la totalidad de su historia". Añade haciendo alusión a la situación política de España en el momento de redactar el artículo: "...debemos manifestar que nuestras circunstancias han cambiado notablemente desde que el Leon español derribó con un esperezo el manchado trono de los Borbones. No que hemos llegado, ni con mucho, al estado que debíamos tener; pero sí que ya no existen muchos de los obstáculos anteriores, y que constante se trabaja por remover los restantes, al mismo tiempo que se plantean los cimientos de la más amplia regeneración. Ya no existen juramentos religiosos en el órden civil, lo cual debió suponer nuestro colega, si no ignoraba, como nosotros nos complacemos en creer, que la unidad religiosa está rota en nuestro país" (GM-QJ: I (1871), 4, pp. 73-79). Como se puede apreciar, en este artículo se perfila también la línea doctrinal de la Gaceta, y más concretamente de su director, Francisco Revueltas, alineado con las ideas republicanas, partidario de la libertad política y crítico con algunos aspectos de la religión en España, además de un marcado acento regeneracionista.

Como apunte final podemos señalar que en la Gaceta Médico-Quirúrgica Jerezana, dirigida por Francisco Revueltas, se aprecia la voluntad de recoger en sus páginas una medicina clínica basada en la observación y en la experiencia, en esta línea están los casos clínicos comentados, ya procedan de la experiencia hospitalaria o de la práctica asistencial particular, destacando por ejemplo la casuística y las reflexiones sobre la difteria, la traqueotomía o las resecciones y amputaciones. Asimismo es significativa la aportación de Federico Rubio y Galí con sus observaciones clínicas sobre los tumores y quistes del ovario, que ya había publicado previamente en Sevilla el cirujano portuense en una monografía editada en 1868. Comprobamos también que estuvo presente la experimentación terapéutica en el hospital jerezano, sirva como ejemplo el cundurango, 
ofreciéndose en la revista el contraste de los resultados propios con los de otros autores respecto a esta medicación. Igualmente se observa una reivindicación de la cirugía humanitaria y conservadora, y un afán por señalar los derroteros de la medicina clínica con el oftalmoscopio y la termometría, o la medicina de laboratorio en el artículo de José Antonio Reynés, o prácticas terapéuticas como la hidroterapia. Tampoco podemos olvidar que Francisco de Barea y Francisco G. Reguera, respectivamente, publican en varios números de la revista las estadísticas mensuales del número de acogidos en el Hospicio Provincial y de los albergados en la Casa de Expósitos en Jerez de la Frontera. Asimismo, la Gaceta ofrece los datos facilitados por los "Jueces Municipales" mensualmente del estado de defunciones y nacimientos, también son de gran interés los informes sobre el estado sanitario en la ciudad, aspectos que quedan recogidos en el índice que presentamos en este trabajo. Todo lo apuntado convierte a la Gaceta en una fuente documental de notable interés para profundizar no solo en la historia del Hospital de Santa Isabel y de las figuras o de los temas tratados, que permiten adentrarnos en los conocimientos médicos y quirúrgicos de la época, como ya hemos apuntado, sino también de otras instituciones asistenciales, temas todos ellos muy necesarios que sean abordados en el futuro para el mejor conocimiento de la medicina y de la sanidad jerezanas de la segunda mitad del siglo XIX.

5. Índice cronológico de la Gaceta Médico-Quirúrgica Jerezana (con observaciones recogidas en el Hospital General de Santa Isabel). Año I (Números 1 al 12) (1871-1872)
(1 tomo) (Biblioteca Central Municipal de Jerez de la Frontera. Signatura: 61 (051) GAC

\section{Gaceta Médico-Quirúrgica Jerezana: I (1871), N. ${ }^{0} 1$ \\ (Martes 15 de agosto de 1871)}

- La Redacción: Artículo prospecto (pp. 1-5).

- Revueltas Carrillo: Croup. Traqueotomía (I). (pp. 5-12).

- Sánchez Balbás, Manuel (Alumno). [Clínica del Hospital]. Laringitis pseudomembranosa: Traqueotomía (pp. 12-17).

- Martínez, Bernardo (Alumno). [Clínica del Hospital]. Gangrena seca de las cuatro extremidades (sic) (pp. 17-19).

- [Hospital]. Sección de Cirugía. Sección de Medicina. Enfermos asistidos en el hospital de Santa Isabel, durante el mes de julio del corriente año (pp. 20-21).

- Variedades. Estado de defunciones y nacimientos ocurridos en esta ciudad en el mes de julio último, según los datos que han tenido la amabilidad de facilitarnos los señores Jueces municipales (pp. 22-23).

- Escuela de Medicina y Cirugía de Sevilla [Incluye convocatoria para el curso 1871 y 1872 . Y la relación de las asignaturas y de los profesores que impartirán las enseñanzas] (pp. 23-24).

\section{Gaceta Médico-Quirúrgica Jerezana: I (1871), N. ${ }^{\circ} 2$}

(Viernes 15 de septiembre de 1871)

- Revueltas Carrillo. Resección y amputaciones (pp. 25-28).

- [Clínica Médica del Hospital]. Fontán y Crespo, Manuel. Peritonitis aguda difusa. Curación (pp. 28-33).

- [Clínica Quirúrgica del Hospital]. Balbás, Manuel (Alumno). Necrosis de 
la tibia. Resección diafisaria parcial de dicho hueso (pp. 33-38).

- [Clínica Quirúrgica del Hospital]. Martínez, Bernardo (Alumno). Fractura de las dos tibias (pp. 40-43).

- Enfermos asistidos en el hospital de Santa Isabel, durante el mes de agosto del corriente año (pp. 44-46).

- Barea, Francisco de. Estado que comprende el número de acogidos en el Hospicio Provincial de esta ciudad, existente en 31 de agosto, los que han estado enfermos durante dicho mes, los curados y muertos y la existencia de enfermos en el expresado día (p. 46).

- Reguera, Francisco G. Estado que manifiesta el movimiento de albergados en la Casa de Expósitos durante el mes de la fecha (agosto) (p. 46).

- Variedades. Estado de defunciones y nacimientos ocurridos en esta ciudad en el mes de Agosto último, según los datos que han tenido la amabilidad de facilitarnos los Señores Jueces Municipales (p. 47).

- Estado sanitario (Agosto) (pp. 47-48).

- Asociación Médico-Farmacéutica española [Constitución de la Junta de Distrito de Jerez] (pp. 48-49).

- Facultad Libre de Farmacia de Cádiz [Firmado por el Secretario Luis María Regife. Cádiz, 1 de septiembre de 1871] (pp. 50-51) (p. 52 en blanco).

\section{Gaceta Médico-Quirúrgica Jerezana: I (1871), N. 3}

(Domingo 15 de octubre de 1871)

- [Nota de la Redacción]. Advertencias (pp. 53-54).

- Rubio y Gali, Federico. Apuntes de don Federico Rubio y Gali sobre los tumores y quistes del ovario y el resultado de su tratamiento médico-quirúrgico [De la Observación número 1 a la 8 ] (Se continuará) (pp. 54-61).

- [Clínica Quirúrgica del Hospital]. Ruiz Berdejo, P. Eclampsia. Parto prematuro artificial. Curación (pp. 62-65).

- Enfermos asistidos en el hospital de Santa Isabel durante el mes de septiembre del corriente año (pp. 66-67).

- Barea, Francisco de P. Estado que comprende el número de acogidos en el Hospicio provincial de esta ciudad, existente en 30 de septiembre, los que han estado enfermos durante dicho mes, los curados y muertos, y la existencia de enfermos en el expresado día (p. 68).

- Reguera, Francisco G. Estado que manifiesta el movimiento de albergados en la Casa de Expósitos durante el mes de la fecha (p. 68).

- Variedades. Estado sanitario (pp. 6869).

- Estado de defunciones y nacimientos ocurridos en esta ciudad en el mes de septiembre último, según los datos que han tenido la amabilidad de facilitarnos los señores Jueces Municipales (p. 69).

- Noticia: Juan José Cambas, director de El Progreso Médico, elegido representante de la Asamblea Médica por el distrito de Utrera y por las provincias de Cádiz y Madrid (p. 70).

- Correspondencia particular de la Gaceta Médico-Quirúrgica (pp. 70-71) (p. 72 en blanco).

\section{Gaceta Médico-Quirúrgica Jerezana: I (1871), N. ${ }^{\circ} 4$}

(Miércoles 15 de noviembre de 1871)

- [Nota de la Redacción]. Advertencia (p. 73).

- De "The Lancet". La profesión en España (pp. 73-75).

- [Contestación a "The Lancet"] (pp. 7579).

- Cortinas, Juan J. Hidrología Médica. De 
la influencia del agua en la naturaleza humana, como medio higiénico y como agente terapéutico (pp. 79-81) (Se continuará).

- Rubio y Gali, Federico. Apuntes de don Federico Rubio y Gali sobre los tumores y quistes del ovario y el resultado de su tratamiento médico-quirúrgico (pp. 8284) (Observaciones número 9 y 10) (Se continuará).

- [Clínica Quirúrgica del Hospital]. Balbás, Manuel (Licenciado). Herida por arma de fuego, interesando el vértice del pulmón izquierdo. Neumonía traumática. Curación (pp. 84-89).

- Enfermos asistidos en el hospital de Santa Isabel durante el mes de octubre del corriente año (pp. 90-91).

- Barea, Francisco de P. Estado que comprende el número de acogidos en el Hospicio provincial de esta ciudad, existente en 31 de octubre, los que han estado enfermos durante dicho mes, los curados y muertos, y la existencia de enfermos en el expresado día (p. 92).

- Reguera, Francisco G. Estado que manifiesta el movimiento de albergados en la Casa de Expósitos durante el mes de la fecha (p. 92).

- Variedades. Estado sanitario (pp. 9293).

- Estado de defunciones y nacimientos ocurridos en esta ciudad en el mes de octubre último, según los datos que han tenido la amabilidad de facilitarnos los señores Jueces Municipales (p. 93).

- Operaciones [En el Hospital de Santa Isabel el Dr. De la Rosa de la Escuela Provincial de Sevilla realizó operaciones de cataratas y enucleación de un ojo. También se realizaron otras operaciones: tallas, ligadura de la crural en un voluminoso tumor aneurismático situado en la parte interna e inferior del muslo. Se elogia las cualidades como cirujano del Dr. Revueltas Carrillo. También se elogia al profesor encargado de la sección médica del hospital D. Manuel Fontan Crespo] (p. 94).

- [Anuncio tomado de El Progreso Médico sobre la Asamblea MédicoFarmacéutica Española. Asamblea Provincial] (pp. 95-96).

- [Noticia sobre la Facultad libre de Farmacia establecida en Cádiz] (p. 96).

- [Estado de salud del decano de la Facultad de Cádiz don Antonio García de Villaescusa] (p. 96).

- [Partidarios de la libertad de enseñanza] (pp. 96-97).

- [Anuncio]. Academia de Farmacia. Lecciones teórico prácticas de Física, Química é Historia Natural, Puras y aplicadas. Tudescos, 39, principal, izquierda. Madrid (pp. 97-98).

\section{Gaceta Médico-Quirúrgica Jerezana: I (1871), N. ${ }^{\circ} 5$}

\section{(Viernes 15 de diciembre de 1871)}

- Revueltas Carrillo. Resección y amputaciones. II. (pp. 101-104).

- Cortina, Dr. Hidrología Médica. De la Influencia del agua en la naturaleza humana, como medio higiénico y como agente terapéutico (pp. 104-106).

- Rubio y Gali, Federico. Apuntes de don Federico Rubio y Gali, sobre los tumores y quistes del ovario y el resultado de su tratamiento médicoquirúrgico (pp. 106-109) (Observaciones número 11, 12, 13 y 14) (Se continuará).

- Fontán y Crespo, Manuel. Pústula maligna. Curación (pp. 109-113).

- [Clínica Quirúrgica del Hospital]. Benítez Navarro, José A. (Alumno observador). Litotomía. Proceder bilateral de Dupuytren. Curación (pp. 113-117). 
- Terán, Francisco (Alumno observador). Necrosis de la tibia. Resección de la totalidad de dicho hueso (pp. 117-123).

- Enfermos asistidos en el Hospital de Santa Isabel en el mes de Noviembre (pp. 124-125).

- Barea, Francisco de P. Estado que comprende el número de acogidos en el Hospicio Provincial de esta ciudad, existente en 30 de noviembre, los que han estado enfermos durante dicho mes, los curados y muertos, y la existencia de enfermos en el expresado día (p. 126).

- Reguera, Francisco G. Estado que manifiesta el movimiento de albergados en la Casa de Expósitos durante el mes de la fecha (p. 126).

- Variedades. Estado sanitario (pp. 126127).

- Estados de defunciones y nacimientos ocurridos en esta ciudad en el mes de noviembre último, según los datos tomados del Registro Civil (p. 127).

- D.E.P. [Noticia del fallecimiento del catedrático y decano de la Facultad de Medicina de Cádiz don Antonio García Villaescusa. En el cementerio discurso de su discípulo el Dr. Juan Ceballos. Intervención de Cayetano del Toro, director de La Crónica Oftalmológica, al que se le critica que en el acto de forma inoportuna cuestionara la figura del médico francés Broussais] (pp. 127128).

- [Noticia]. Publicación del primer número de La Época Médica, periódico quincenal, dirigido en Sevilla por el Dr. Luis Góngora, catedrático de Dermatología en la Facultad libre de Sevilla (p. 128).

- [Noticia]. Revista Cubana. Se ha recibido los Anales de la Real academia de ciencias médicas, físicas y naturales, etc., que se publica en la Habana bajo la dirección de los Dres. D. Antonio
Mestre y D. Felipe F. Rodríguez (p. 128).

- [Errata notable] (p. 128).

\section{Gaceta Médico-Quirúrgica Jerezana: I (1872), N. ${ }^{\circ} 6$}

(Lunes 15 de enero de 1872)

- [Clínica Quirúrgica del Hospital]. Balbás, Manuel (Licenciado). Hemorragia uterina. Parto prematuro artificial. Muerte (pp. 129-138).

- Cortina, Dr. Hidrología Médica. De la influencia del agua en la naturaleza humana, como medio higiénico y como agente terapéutico (pp. 139-141).

- Rubio y Gali, Federico. Apuntes de don Federico Rubio y Gali, sobre los tumores y quistes del ovario y el resultado de su tratamiento médicoquirúrgico (pp. 141-144) (Observaciones número 15 y 16 ) [Continuará].

- [Clínica Médica del Hospital]. Martínez, Bernardo (Alumno observador). Congestión cerebral activa. Asfasia (sic). Curación rápida (pp. 144-147).

- Enfermos asistidos en el hospital de Santa Isabel durante el mes de diciembre del corriente año (pp. 148149).

- Barea, Francisco de P. Estado que comprende el número de acogidos en el Hospicio provincial de esta ciudad, existente en 31 de diciembre, los que han estado enfermos durante el dicho mes, los curados y los muertos, y la existencia de enfermos en el expresado (p. 150).

- Barea, Francisco de P. Estado general del movimiento de enfermos, curados y muertos en el Hospicio provincial de esta ciudad, durante el año de 1871 (p. 150). 
- Reguera, Francisco G. Estado que manifiesta el movimiento de albergados en la Casa de Expósitos durante el mes de la fecha (p. 151).

- Reguera, Francisco G. Estado general del movimiento de albergados en la Casa de expósitos durante el año de 1871 (p. 151).

- Variedades. Estado sanitario (p. 152).

- Estado general de los enfermos, invadidos, curados y muertos en Jerez durante el año 1871 (p. 152).

- Estado de defunciones y nacimientos ocurridos en esta ciudad en el mes de diciembre último, según los datos tomados del registro civil (p. 153).

- Estado general de las defunciones y nacimientos ocurridos en esta ciudad durante el año 1871 según los datos tomados del registro civil (pp. 153-154).

- Del cundurango (p. 155).

- [Polémica con el director de La Crónica Oftalmológica sobre Broussais] (pp. 155-156).

- [Errata importante] (p. 156).

\section{Gaceta Médico-Quirúrgica Jerezana: I (1872), N. ${ }^{\circ} 7$ \\ (Jueves 15 de febrero de 1872)}

- Advertencia (A partir de este número se publicará la revista una vez cada mes, sin día determinado) (p. 157).

- Revueltas Carrillo. Resección y amputaciones. III (pp. 157-160).

- Cortina, Dr. Hidrología médica. De la influencia del agua en la naturaleza humana, como medio higiénico y como agente terapéutico (pp. 160-162).

- Rubio y Gali, Federico. Apuntes de don Federico Rubio y Gali, sobre los tumores y quistes del ovario y el resultado de su tratamiento médicoquirúrgico (pp. 162-166) (Observaciones número 17 y 18) (Se continuará).

- [Clínica Quirúrgica del Hospital]. Martínez, Bernardo (Alumno observador). Tumor escirroso de la mama derecha. Ramificaciones. Operación. Corte de la subclavia. Ligadura. Muerte á los tres meses (pp. 167-173).

- Benítez Navarro, José A. (Alumno observador). Catarro vexical crónico. Estrecheces de la uretra. Operación. Completa curación (pp. 174-177).

- Enfermos asistidos en el Hospital de Santa Isabel en el mes de enero (pp. 178179).

- Estado de las defunciones y nacimientos ocurridos en esta ciudad en el mes de enero último, según los datos tomados del registro civil (p. 180).

- Barea, Francisco de P. Estado que comprende el número de acogidos en el Hospicio provincial de esta ciudad, existente en 31 de enero, los que han estado enfermos durante dicho mes, los curados y los muertos, y la existencia de enfermos en el expresado día (p. 181).

- Reguera, Francisco G. Estado que manifiesta el movimiento de albergados en la Casa de Expósitos durante el mes de la fecha (pp. 181-182).

- Estado sanitario (p. 182).

- Variedades. Revueltas Carrillo: D. Antonio García de Villaescusa, Doctor en Medicina y Cirugía, catedrático y Decano de la Facultad de Cádiz (pp. 182-185) (Se continuará).

- Más sobre el cundurango (p. 186).

- Nueva publicación. Primer cuaderno del Tratado práctico elemental de Patología sifilítica y venérea, de los Dres. M.L. Belhomme y M. Aime Martin, traducido al castellano por el Dr. Don Antonio Cordero Ferrer (p. 186).

- [Queja]. ¿Por qué El Pabellón Médico no visita nuestra redacción? (p. 186).

- Cambas, Dr. Solemnidad académica 
[Toma de posesión de su cargo del nuevo decano de la Facultad de Medicina de Cádiz, el Excmo. Sr. D. Francisco Flores Arena. Texto tomado de El Progreso Médico de Cádiz] (pp. 187-188).

- [Lápida y retrato en la Escuela de Medicina de Sevilla dedicados al catedrático malogrado Dr. D. Gabriel Tejada] (p. 188).

- Cifras horribles [Muertos en campos de batallas] (p. 188).

\section{Gaceta Médico-Quirúrgica Jerezana: I (1872), N. ${ }^{\circ} 8$}

(Jueves 25 de marzo de 1872)

- Advertencia [Incumplimientos de pagos suscriptores de la revista y dificultades "para esta empresa"] (p. 189).

- Cortina, Dr. Hidrología Médica. De la influencia del agua en la naturaleza humana, como medio higiénico y como agente terapéutico (pp. 189-191) (Se continuará).

- Rubio y Gali, Federico. Apuntes de don Federico Rubio y Gali, sobre los tumores y quistes del ovario y el resultado de su tratamiento médico-quirúrgico (pp. 192194) (Observación número 19) (Se continuará).

- [Clínica Médica del Hospital]. Martínez, Bernardo (Alumno observador). Parálisis esencial con asfasia (sic). Curación (pp. 194-196).

- [Clínica Quirúrgica del Hospital]. Solís, Eduardo (Alumno observador). Herida contusa con fractura del antebrazo. Amputación (197-206).

- Enfermos asistidos en el Hospital de Santa Isabel en el mes de febrero (pp. 207209).

- Barea, Francisco de P. Estado que comprende el número de acogidos en el Hospicio provincial de esta ciudad, existente en 29 de febrero, los que han estado enfermos durante dicho mes, los curados y muertos, y la existencia de enfermos en el expresado día (p. 209).

- Reguera, Francisco G. Estado que manifiesta el movimiento de albergados en la Casa de Expósitos durante el mes de la fecha (p. 209).

- Estado de las defunciones y nacimientos ocurridos en esta ciudad en el mes de febrero último, según los datos tomados del registro civil (p. 210).

- Estado sanitario (p. 211).

- Variedades. [Deducimos que el autor es Revueltas Carrillo]. D. Antonio García de Villaescusa, Doctor en Medicina y Cirugía, catedrático y Decano de la Facultad de Cádiz. II. (pp. 211-214) (Se continuará).

- Visita importante [Visita el hospital el Excmo. Sr. Dr. D. Melchor Sánchez Toca. Recibido por el Dr. Revueltas Carrillo, el conde de Monte-Gil y la superiora sor Tomasa Ochoa] (pp. 214-216).

- El cáncer y el cundurango (pp. 216-217).

- Noticia [Trabajo de Cayetano del Toro sobre la Importancia y adelantos de la oftalmología y resumen estadístico de la clínica oftalmológica] (p. 217).

- Recibido en la redacción el anuario El Relámpago Médico del Dr. Juan Marsillach y Parera (p. 217).

- Más publicaciones [Intercambio de nuevos periódicos: Revista MédicoQuirúrgica, La Gaceta Escolar, de Madrid, La Voz de la Juventud, de Sevilla, y The Chloral Review, de Londres] (p. 217).

- Real Academia de Medicina de Madrid. Programa de premios para 1872 (pp. 218219).

- Navas y Román, Leonardo de. Discurso leído ante la Facultad de Medicina de Cádiz para el grado de doctor el 28 de enero de 1872: "Determinar ó señalar los inconvenientes y perjuicios que resultan a los individuos, la familia y la sociedad, por las 
faltas y engaños en el cumplimiento de las funciones de la generación" (p. 220) (Se continuará).

\section{Gaceta Médico-Quirúrgica Jerezana: I (1872), N. ${ }^{\circ} 9$}

(Sábado 27 de abril de 1872)

- Revueltas Carrillo. Resección y amputaciones. IV (PP. 221-224).

- Rubio y Gali, Federico. Apuntes de don Federico Rubio y Gali, sobre los tumores y quistes del ovario y el resultado de su tratamiento médico-quirúrgico (pp. 224228) (Observación número 20) (Se continuará).

- [Clínica Médica del Hospital]. Martínez, Bernardo (Alumno observador). Ascitis dependiente de un infarto del hígado. Complicación accidental. Curación (pp. 229-231).

- [Clínica Quirúrgica del Hospital]. Terán Francisco (Alumno observador). Carcinomas tratados por la pomada arsenical. Curaciones (pp. 231-236).

- Enfermos asistidos en el Hospital de Santa Isabel en el mes de marzo (pp. 237238).

- Estado de las defunciones y nacimientos ocurridos en esta ciudad en el mes de marzo último, según los datos tomados del registro civil (p. 239).

- Barea, Francisco de P. Estado que comprende el número de acogidos en el Hospicio provincial de esta ciudad, existente en 31 de marzo, los que han estado enfermos durante dicho mes, los curados y muertos, y la existencia de enfermos en el expresado día (p. 240).

- Reguera, Francisco G. Estado que manifiesta el movimiento de albergados en la Casa de expósitos durante el mes de la fecha [sin datos, no han sido enviados por el Sr. Administrador de la Casa de Expósitos] (p. 240).
- Estado sanitario (pp. 240-241).

- Variedades. [Deducimos que el autor es Revueltas Carrillo]. D. Antonio García de Villaescusa, Doctor en Medicina y Cirugía, catedrático y Decano de la Facultad de Cádiz. (pp. 241-242) (Se continuará).

- Nuevas publicaciones [La Unión Médica, revista científica y profesional, órgano del Centro Médico-farmacéutico castellonense, y El Ateneo Lorquino, revista científica, literaria y de bellas artes. Y el libro Novísimo formulario magistral de A. Bouchardat. Y el trabajo del Dr. Da Costa Alvarenga de Lisboa: Thermosémiologie et Thermacologie] (pp. 242-243).

- Real Academia de Medicina de Madrid. Programa de premios para el año de 1873 (pp. 243-244).

- [Anuncio]: “Creyendo de sumo interés la Memoria del Dr. Moreau Wolf sobre la curación de las estrecheces de la uretra, la hemos traducido, y dedicamos a ella el último pliego, siendo esta la primera obra que forme la biblioteca de nuestro periódico" (p. 244).

\section{Gaceta Médico-Quirúrgica Jerezana: I (1872), N. ${ }^{\circ} 10$ \\ (Martes 28 de mayo de 1872)}

- Cortina, Dr. Hidrología Médica. De la influencia del agua en la naturaleza humana, como medio higiénico y como agente terapéutico (pp. 245-247).

- Gerard, Dr. (De Breuning, Austria). Comunicaciones médicas alemanas (pp. 248-253).

- [Clínica Quirúrgica del Hospital]. Gracia, Antonio de (Alumno observador). Inflamación del escroto. Terminación por gangrena. Eliminación completa de aquel. Curación (pp. 253-257).

- Enfermos asistidos en el hospital de Santa 
Isabel (pp. 258-259).

- Estado de las defunciones y nacimientos ocurridos en esta ciudad en el mes de abril último, según los datos tomados del registro civil (p. 260).

- Barea, Francisco de P. Estado que comprende el número de acogidos en el Hospicio provincial de esta ciudad, existente en 31 de abril, los que han estado enfermos durante dicho mes, los curados y muertos, y la existencia de enfermos en el expresado día (p. 261).

- Reguera, Francisco G. Estado que manifiesta el movimiento de albergados en la Casa de Expósitos durante los meses de marzo y abril (p. 261).

- Estado sanitario (pp. 261-262).

- Revueltas Carrillo. De la Thermosémiologie et Thermacologie analise de la loi Thermo-differentielle etc. Por le Dr. P. F. da Costa Alvarenga (pp. 262-264).

- Noticia: [El 18 de abril, "una de las recogidas en la sala de Maternidad, del Hospital de esta población, dio a luz en parto natural y feliz, tres criaturas (...). La paciente ha convalecido sin alteración ninguna en breve tiempo, y de los tres fetos trasladados á la casa de expósitos, ha muerto solamente uno, habiendo vivido un mes, y sobreviviendo aun los otros dos"] (p. 264).

- Noticia: [Jóvenes hacen un llamamiento para formar un Congreso Escolar. En la revista realizan una defensa de la libertad de enseñanza: "Aprendan ahí los tiranos de la libertad, de la de enseñanza particularmente, y vean los resultados de ella que creían que bajo su influjo pudiera cerrarse el sagrado templo de la ciencia" (p. 264).

- [Nuevas publicaciones]: La Oficina farmacéutica ó Repertorio universal de farmacia práctica, primer cuadernillo, de Carlos Bailly-Bailliere. Ejemplar de las Cartas médicas franco-prusianas de Salvador
Badia (p. 265).

- [Intercambios de revistas y erratas] (pp. 265-266).

- Navas y Román, Leonardo de. Discurso leído ante la Facultad de Medicina de Cádiz, por el licenciado en medicina y cirugía don Leonardo de Navas y Román, en el acto de recibir la investidura de doctor en dicha Facultad, el día 28 de enero de 1872 (continuación) (pp. 266268) (Se continuará).

\section{Gaceta Médico-Quirúrgica Jerezana: I (1872), N. ${ }^{\circ} 11$ \\ (Domingo 30 de junio de 1872)}

- Revueltas Carrillo. Resección y amputación. V. (pp. 269-272).

- [Clínica Quirúrgica particular del Dr. Revueltas Carrillo]. Balbás, Manuel (Licenciado). Laringitis pseudomembranosa. Traqueotomía. Curación (pp. 272-279).

- Rubio y Gali, Federico. Apuntes de don Federico Rubio y Gali sobre los tumores y quistes del ovario y el resultado de su tratamiento médico-quirúrgico (pp. 279284) (Observación número 21) (Se continuará).

- Estado sanitario (p. 284).

- Enfermos asistidos en el hospital de Santa Isabel en el mes de mayo (pp. 285-287).

- Barea, Francisco de P. Estado que comprende el número de acogidos en el Hospicio provincial de esta ciudad, existente en 31 de mayo, los que han estado enfermos durante dicho mes, los curados y muertos, y la existencia de enfermos en el expresado día (p. 287).

- Reguera, Francisco G. Estado que manifiesta el movimiento de albergados en la Casa de Expósitos durante el mes de mayo (p. 287).

- Estado de las defunciones y nacimientos ocurridos en esta ciudad en el mes de 
mayo último, según los datos del registro civil (p. 288).

- Variedades. [Agradecimiento al Dr. D. Miguel Moreno, profesor clínico del Hospital general de Cádiz, por una copia fotografiada de dos voluminosos cálculos vexicales, extraídos por él (talla hipogástrica)] [Felicitación a don Bernardo Martínez y Álvarez, compañero de redacción, por haber alcanzado la licenciatura en el mes de junio] [El Dr. Juan José Cambas, director de El Progreso Médico, ha sido distinguido como Socio Corresponsal de la Sociedad de Ciencias Médicas de Lisboa] (p. 289).

- Navas y Román, Leonardo de. Discurso leído ante la Facultad de Medicina de Cádiz, por el licenciado en medicina y cirugía don Leonardo de Navas y Román, en el acto de recibir la investidura de doctor en dicha Facultad, el día 28 de enero de 1872 (continuación) (pp. 289292) (Se continuará).

\section{Gaceta Médico-Quirúrgica Jerezana: I (1872), N. ${ }^{\circ} 12$ \\ (Domingo 31 de julio de 1872)}

- Reynés, José Antonio. Del estado presente de la Medicina y sus tendencias para el porvenir (pp. 293300).

- Enfermos asistidos en el Hospital de Santa Isabel en el mes de junio (pp. 301302).

- Estado de las defunciones y nacimientos ocurridos en esta ciudad en el mes de junio último, según los datos tomados del registro civil (p. 303).

- Barea, Francisco de P. Estado que comprende el número de acogidos en el Hospicio provincial de esta ciudad, existente en 30 de junio, los que han estado enfermos durante dicho mes, los curados y muertos, y la existencia de enfermos en el expresado día (p. 304).

- Reguera, Francisco G. Estado que manifiesta el movimiento de albergados en la Casa de Expósitos durante el mes de junio (p. 304).

- Navas Román, Leonardo de. Discurso leído ante la Facultad de Medicina de Cádiz, por el licenciado en medicina y cirugía don Leonardo de Navas y Román, en el acto de recibir la investidura de doctor en dicha Facultad, el día 28 de enero de 1872 (continuación) (pp. 305-308) (Final).

[Página desplegable]. Fontán y Crespo Manuel; Hernández, Francisco J.; Revueltas Carrillo, Francisco. Cuadro estadístico del movimiento ocurrido durante el año de 1871 en el Hospital General de Santa Isabel de esta ciudad, a cargo de los profesores que suscriben. Jerez de la Frontera, 31 de diciembre de 1871.

Agradecimientos: Al Archivo y la Biblioteca Municipal de Jerez de la Frontera, muy especialmente a Cristóbal Orellana González, Eulalia Barea, José Luis Jiménez García y Antonio Santiago Pérez. Y a el Archivo de la Universidad de Cádiz, muy especialmente a Clemencia Cruz Rodríguez, Rosario Marín Alfaro y María José Romero Melero.

\section{FUENTES DOCUMENTALES}

- Sobre la revista estudiada:

"Gaceta Médico-Quirúrgica Jerezana, con observaciones recogidas en el Hospital General de Santa Isabel". Año I (Números 1 al 12) (1871-1872). 12 números. Números: Número 
1 (Martes, 15 de agosto de 1871); Número 2 (Viernes, 15 de septiembre de 1871); Número 3 (Domingo, 15 de octubre de 1871); Número 4 (Miércoles, 15 de Noviembre de 1871); Número 5 (Viernes, 15 de diciembre de 1871); Número 6 (Lunes, 15 de enero de 1872); Número 7 (Jueves, 15 de febrero de 1872); Número 8 (Jueves, 25 de marzo de 1872); Número 9 (Sábado 27 de Abril de 1872); Número 10 (Martes 28 de mayo de 1872); Número 11 (Domingo, 30 de junio de 1872); Número 12 (Domingo, 31 de julio de 1872). Localización: Encuadernación en un tomo que contiene los 12 números. Biblioteca Central Municipal de Jerez de la Frontera. Signatura: 61 (051) GAC.

Abreviaturas de los números de esta revista utilizadas en las citas internas del artículo: GM-QJ 1; GM-QJ 2; GM-QJ 3; GMQJ 4; GM-QJ 5; GM-QJ 6; GM-QJ 7; GM-QJ 8; GM-QJ 9; GM-QJ 10; GM-QJ 11; GM-QJ 12.

- Sobre algunos de los autores que publicaron en la revista o que recibieron formación práctica en el Hospital de Santa Isabel de Jerez de la Frontera (médicos, alumnos de medicina, practicante y matronas):

- Expediente de alumno de Francisco de Paula Revueltas y Montel en la Facultad de Medicina de Cádiz. FM 83(1)-1 (Archivo de la Universidad de Cádiz, AUCA).

- Defunción de Francisco de Paula Revueltas y Montel. Cf. Libro de Cementerio 53, 1887, número de registro 1012, f. 22 (Archivo Municipal de Jerez de la Frontera). Abreviatura: Libro de Cementerio 53, 1887, f. 22, AMJF).

- Renuncia del cargo de médico del Hospital de Santa Isabel por Manuel Fontán. Sesión Ordinaria 6 de noviembre de 1882 (punto 3. ${ }^{\circ}$ ). Acta Capitular 1882-1883. N. 279. Archivo
Municipal de Jerez de la Frontera. Abreviatura: A.M.J.F. En sesión extraordinaria de 22 de noviembre de 1882 (punto 9. ${ }^{\circ}$ ) consta que se nombró Facultativo interino del Hospital a don Teodoro Orozco.

- Expediente de alumno de Juan José Cortinas Pérez en la Facultad de Medicina de Cádiz. FM 96 (1)-4 (Archivo de la Universidad de Cádiz, AUCA).

- Expediente de alumno de Pedro Ruiz Berdejo en la Facultad de Medicina de Cádiz. FM 3 (1)-7 (Archivo de la Universidad de Cádiz, AUCA).

- Expediente de alumno de Leonardo Navas y Román en la Facultad de Medicina de Cádiz. FM 43 (2)-15 (Archivo de la Universidad de Cádiz, AUCA).

- Navas y Román, Leonardo (1872): Determinar ó señalar los inconvenientes y perjuicios que resultan á los individuos, la familia y la sociedad, por las faltas y engaños en el cumplimiento de las funciones de la generacion. Discurso leído ante el claustro de la Facultad de Medicina de Cádiz, por el licenciado en medicina y cirugía ( ) en el acto de recibir la investidura de Doctor en dicha Facultad, el día 28 de enero de 1872. Cádiz: Imprenta y Litografía de la Revista Médica, de D. Federico Joly, calle de la Bomba, núm. 1 (Esta tesis impresa se puede consultar en el expediente personal de Leonardo Navas y Román, citado anteriormente, que se encuentra en AUCA).

- Expediente de alumno de Bernardo Martínez Álvarez en la Facultad de Medicina de Cádiz. C-15 (1)-5 FM (Archivo de la Universidad de Cádiz, AUCA).

- Expediente de alumno de Manuel Balbás Martín en la Facultad de Medicina de Cádiz. C-10 (1)-1FM 
(Archivo de la Universidad de Cádiz, AUCA).

- Expediente de alumno de José Antonio Benítez Navarro en la Facultad de Medicina de Cádiz. C-21 (1)-8FM (Archivo de la Universidad de Cádiz, AUCA).

- Expediente de alumno de Francisco Terán Salguero en la Facultad de Medicina de Cádiz. FM 16(2)-14 (Archivo de la Universidad de Cádiz, AUCA).

- Expediente de alumno de Eduardo Solís Bazán en la Facultad de Medicina de Cádiz. FM 15(1)-2 (Archivo de la Universidad de Cádiz, AUCA).

- Expediente de alumno de Antonio de Gracia Rodríguez en la Facultad de Medicina de Cádiz. FM 15(2)-9 (Archivo de la Universidad de Cádiz, AUCA).

- Expediente de alumno de Vicente Marín González en la Facultad de Medicina de Cádiz (carrera de Practicante). C-55(2)-51FM (Archivo de la Universidad de Cádiz, AUCA).

- Expediente de alumna de Inés de Peña y Vargas en la Facultad de Medicina de Cádiz (carrera de Matrona). C-51(1)2FM (Archivo de la Universidad de Cádiz, AUCA).

- Expediente de María del Carmen Molinillo Marín en la Facultad de Medicina de Cádiz (carrera de Matrona). C-55(1)-12FM (Archivo de la Universidad de Cádiz, AUCA).

\section{- Sobre el Hospital de Santa Isabel de Jerez de la Frontera:}

- Legajo n. $339 . \quad$ Expediente 9992. Inauguración del Hospital General de Santa Isabel. 1841 (Archivo Municipal de Jerez de la Frontera, abreviatura: AMJF).

- Legajo n. . $\quad 340 . \quad$ Expediente 10047. Solicitud Hermanas de la Caridad. 1853
(AMJF).

- Legajo n.. $\quad 342 . \quad$ Expediente 10094. Construcción del Departamento de Mujeres. 1843 (AMJF).

- Legajo n.o 342. Expedientes 1009310123. Expedientes sobre obras y reparaciones en Hospital de Santa Isabel de Jerez de la Frontera (décadas de los 50 y 60 del siglo XIX) (AMJF).

- Legajo n.o 1406. Expediente 27307-bis. Hospital Municipal de Santa Isabel. Administración. Memoria de 1954 (AMJF).

- Reglamento del Hospital General de Santa Isabel de Jerez de la Frontera (1874). Jerez: Imprenta del Guadalete (Abreviatura para la cita interna: Reglamento, 1874).

\section{BIBLIOGRAFÍA}

- Albarracín-Teulón, A. (1975). La polémica CreusRubio en torno a la resección subperiostica (1861). En Actas del IV Congreso Española de Historia de la Medicina (Granada, 1973). (Vol. 1, 265-272). Granada: Secretariado de Publicaciones de la Universidad de Granada y Obra Cultural de la Caja de Ahorros de Granada.

- Álvarez-Sierra, J. (1947). El doctor D. Federico Rubio. Vida y obra de un cirujano genial. Madrid: Editora Nacional.

- Camacho-Iglesias, A. (2006). El niño en la prensa médica del siglo XIX en el distrito universitario hispalense. Tesis doctoral. Cádiz: Universidad de Cádiz.

- Campos-Marín, R. (2003). Monlau, Rubio, Giné. Curar y gobernar. Medicina y liberalismo en la España del siglo XIX. Madrid: Novatores.

- Caro-Cancela, D. (1990). Burguesía y jornaleros en el sexenio democrático (1868-1874). Jerez: Colección Ensayo Caja de Ahorros de Jerez de la Frontera.

- Caro-Cancela, D. (2018). La ciudad republicana: Jerez de la Frontera a finales de 1868. En: Caro-Cancela, D. (Ed.): La revolución de 1868 en Andalucía (pp. 71-97). Cádiz: Ediciones Presea, S. L.

- Carrillo-Martos, J. L. et al. (2002): Federico Rubio y Galí (1827-1902): Estudio documental y bibliográfico. El Puerto de Santa María: Biblioteca de Temas Portuenses.

- Carrillo-Martos, Juan L. (2003). Medicina y sociedad en la España de la segunda mitad del siglo XIX: una aproximación a la obra de Federico Rubio y Galí (1827- 
1902. El Puerto de Santa María: Ayuntamiento de El Puerto de Santa María y Asociación para la Formación, Investigación y Asistencia Médica de Andalucía "Federico Rubio".

- Doña-Nieves, F. (1987a). El doctor Revueltas Montel (1839-1887) y su labor como alcalde de Jerez en tiempos de la primera República española. Cádiz: Caja de Ahorros de Jerez.

- Doña-Nieves, F. (1987b). La especialidad tocoginecológica en la prensa médica gaditana (18201886). Anales de la Real Academia de Medicina y Cirugía de Cádiz, XXIII, 1, 33-105.

- Doña-Nieves, F. (1987c). La especialidad tocoginecológica en la prensa médica gaditana (18201886). Anales de la Real Academia de Medicina y Cirugía de Cádiz, XXIII, 2, 47-77.

- Doña-Nieves, F. (1998). Los orígenes de la medicina del trabajo en España. Aportación de la prensa médica andaluza del siglo XIX (1820-1898). Tesis doctoral. Cádiz: Universidad de Cádiz.

- Doña-Nieves, F., y Herrera-Rodríguez, F. (1990). El vino de Jerez, como agente higiénico y terapéutico, en la medicina del siglo XIX. En: Libro de Actas de las "XI Jornadas de Viticultura y Enología de Tierra de Barros". Zafra, 337-348.

- Doña, F. y Herrera, F. (1991). Contribución de Jerez de la Frontera a los Congresos Médicos Andaluces del siglo XIX. En: Libro de Actas del IX Congreso Nacional de Historia de la Medicina. Zaragoza. Tomo III, 907-920.

- Fernández-Lozano, E. Ma (2018). Indización y estudio crítico de «La Crónica Oftalmológica» (1871-1883). Trabajo Fin de Grado (Máster). Cádiz: Facultad de Medicina. Disponible en: https://rodin.uca.es/xmlui/handle/10498/20696 (Consultado el 27 de enero de 2019).

- Góngora, A. de (1900). El periodismo jerezano. Apuntes para su historia. Jerez: Imprenta El Guadalete.

- Granjel, Luis S. (1986). Medicina española contemporánea. Salamanca: Ediciones Universidad de Salamanca.

- Guedea-Calvo, L. (1890). Discurso sobre la práctica actual de la ovariotomía especialmente en lo que se refiere al tratamiento del pedículo y á la antisepsis. Madrid: Establecimiento tipográfico de Fortanet.

- Guisado-Cuéllar, A. (2017). Cayetano del Toro y Quartiellers (1942-1915): "El padre del pueblo". Setenta y dos años claves en la historia de Cádiz. Cádiz. Diputación de Cádiz.

- Gutiérrez, E. (1903). Biografía del Excmo. É Illmo. Señor D. Federico Rubio y Gali. Madrid: Est. Tipo. De la viuda é hijos de M. Tello.

- Herrera-Rodríguez, F. (1986). La enseñanza libre de practicantes y matronas en el Cádiz de 1868. Anales de la Real Academia de Medicina y Cirugía de Cádiz, XXII, 2,
99-105.

- Herrera-Rodríguez, F. (1987). La investigación científica en la Facultad de Medicina de Cádiz a través de las tesis doctorales producidas en la misma en el siglo XIX. Tesis doctoral. Microfichas. Barcelona: Universidad de Cádiz.

- Herrera-Rodríguez, F. (1989). La titulación de matronas en la Facultad de Medicina de Cádiz durante el «sexenio revolucionario» (1868-1874). TokoGinecología Práctica, XLVIII, 539, 230-236.

- Herrera-Rodríguez, F. (1992-93). La titulación de practicantes y matronas en la Facultad de Medicina de Cádiz en el sexenio revolucionario (1868-1874). En: Herrera-Rodríguez, F.: Estudios sobre las profesiones auxiliares sanitarias en Cádiz (siglos XIX y XX). Anales de la Universidad de Cádiz, IX-X, 231-250.

- Herrera-Rodríguez, F. (1994). El médico jerezano Juan José Cambas Gallego (1833-1877). Revista de Historia de Jerez, 2, 83-90.

- Herrera-Rodríguez, F. (1999): La Casa de Maternidad de Cádiz a finales del siglo XIX. Híades. Revista de Historia de la Enfermería, 5-6, 271-283.

- Herrera-Rodríguez, F. (2000). Gavilla de médicos gaditanos. Cádiz: Quorum libros editores.

- Herrera-Rodríguez, F. y Lasarte Calderay, J.E.: (1996). La prensa andaluza de los practicantes y matronas (1916-1939). En: I Congreso Nacional Nacional de Historia de la Enfermería. Libro de Ponencias y Comunicaciones (pp. 169-174). Barcelona: Fundación Uriach; E.U. de Enfermería, Fisioterapia y Podología de la Complutense; E.U. de Enfermería del Hospital General Universitario de Valencia.

- Herrera-Rodríguez, F. (2002a). El Dr. Federico Rubio y la renovación de la medicina española (1827-1902). Cádiz: Ayuntamiento de El Puerto de Santa María.

- Herrera-Rodríguez, F. (2002b). Un acercamiento a la obra de Federico Rubio y Gali (1827-1902). Revista de Historia de El Puerto, 29, 63-88.

- Herrera-Rodríguez, F. (2008) Archivos y hemerotecas: espacios para la investigación de la Historia de la Enfermería. Híades. Revista de Historia de la Enfermería, 10, 71-110.

- Herrera-Rodríguez, F. (2010). Cayetano del Toro y Quartiellers (1842-1915). En Bustos, M. (dir.): Centenario de la Real Academia Hispanoamericana (19102010).I. Alrededor de los Cien Años de Historia y Vida Académicas (pp. 207-236). Cádiz: Real Academia Hispanoamericana de Ciencias, Artes y Letras.

- Laín-Entralgo, P. (1977-78). Medicina y Sociedad en la obra de Federico Rubio. En: Sesión de apertura del curso académico 1977-78. Madrid: Instituto de España, pp. 53-62.

- Larra y Cerezo, A. (1905). Historia resumida del periodismo médico en España. Madrid: La Medicina Militar Española. 
- Lasarte-Calderay, J.E. (1995). La prensa de las profesiones auxiliares sanitarias en Andalucía. Estudio socio-profesional (1916-1939). Tesis doctoral. Microficha. Barcelona: Universidad de Cádiz.

- Lasarte-Calderay, J.E., y Herrera-Rodríguez, F. (1992). Noticias hispanoamericanas en la prensa andaluza de los auxiliares sanitarios (1916-1936). Anales de la Real Academia de Medicina y Cirugía de Cádiz, XXVIII, 1, 349-358.

- Leiva, J. (1982). El periodismo en Jerez. Siglo XIX. Jerez de la Frontera: Publicaciones del Centro de Estudios Históricos Jerezanos.

- López-Piñero, J.M. (1983). Rubio Galí, Federico. En: Diccionario histórico de la ciencia moderna en España. Barcelona: Ediciones Península, pp. 269-273.

- López-Piñero, J.M. (1992). Las ciencias médicas en la España del siglo XIX. En López-Piñero, José M.: La Ciencia en la España del siglo XIX (pp. 193-240). Madrid: Marcial Pons.

- López-Piñero, J. M. y Terrada, M. L. (1980). Las etapas históricas del periodismo médica en España. Estudio bibliométrico. En Albarracín Teulón, A.; LópezPiñero, José M${ }^{\mathrm{a}}$.; Granjel, Luis S.: Medicina e Historia (pp. 163-191). Madrid: Editorial de la Universidad Complutense.

- López-Piñero, J. M. y Terrada, M. L. (1990). Bibliographia Médica Hispánica, 1475-1950. Volumen VIII. Revistas, 1736-1950. Valencia: Instituto de Estudios Documentales e históricos sobre la Ciencia. Universidad de Valencia-CSIC.

- López-Piñero, J. M. y Terrada, M. L. (1991). Bibliographia Médica Hispánica, 1475-1950. Volumen IX. Bibliometría de las revistas, 1736-1950. Valencia: Instituto de Estudios Documentales e históricos sobre la Ciencia. Universidad de Valencia-CSIC.

- Maraver-Eyzaguirre, F. (1982). El Periódico de la Sociedad Médico-Quirúrgica (1820-1831): Indización y estudio crítico. Tesis doctoral. Cádiz: Universidad de Cádiz. Cádiz.

- Marín-Paz, Antonio J. (2013). El asociacionismo histórico de los practicantes y la defensa de su profesión. Enfermería Gaditana. Revista del Excmo. Colegio Oficial de Enfermería de la Provincia de Cádiz, 24, 21-23.

- Mariscal-Trujillo, A. (2001). La Sanidad Jerezana 18001975 (Apuntes históricos). Cádiz: Editorial Eje.

- Mariscal-Trujillo, A. (2015). Hermano Adrián. Limosnero de Dios. Vida, obra y aventuras del Hermano Adrián del Cerro. Orden Hospitalaria de San Juan de Dios. Granada: Ediciones Alsur, S.C.A.

- Márquez-Espinós, C. (1988). La introducción de la anestesiología en España a través de la prensa médica gaditana del siglo XIX. Tesis doctoral. Microfichas. Barcelona: Universidad de Cádiz.

- Márquez-Espinós, C. y Orozco-Acuaviva, A. (1984).
La Anestesia en «La Crónica de los Hospitales» (1849-1850) de Antonio de Gracia. Boletín Informativo del Excelentísimo Colegio Oficial de Médicos de la Provincia de Cádiz, 5, 5-9.

- Matilla, V. (1982). Galería de presidentes de la Real Academia Nacional de Medicina. Madrid: Instituto de España.

- Méndez Álvaro, F. (1978). Historia del periodismo médico y Farmacéutico en España (Introducción, edición e índices de J. Riera). Valladolid: Servicio de Publicaciones de la Universidad de Valladolid.

- Olagüe de Ros, G., y Paredes-Salido, F. (1983). Análisis histórico de una revista isleña del siglo XX: La Medicina Práctica (1902-1915). Su aportación a la Medicina y a la Farmacia de la época. Medicina Militar, 39 (4), 76-79.

- Orozco-Acuaviva, A. (1962). El doctor don Cayetano del Toro y Quartiellers. Archivo Iberoamericano de Historia de la Medicina y Antropología Médica, XIV, 261284.

- Orozco-Acuaviva, A. (1977). Federico Rubio, el gran maestro. Anales de la Real Academia de Medicina y Cirugía de Cádiz, XIII, 2, 17-32.

- Orozco-Acuaviva, A. (1980a). La prensa médica gaditana. Boletín Informativo del Excelentísimo Colegio Oficial de Médicos de la Provincia de Cádiz, 1, 6-8.

- Orozco-Acuaviva, A. (1980b). El Periódico de la Sociedad Médico-Quirúrgica de Cádiz (1820-1831). Boletín Informativo del Excelentísimo Colegio Oficial de Médicos de la Provincia de Cádiz, 2, 5-9.

- Orozco-Acuaviva, A. (1981a). La Crónica de los Hospitales de don Antonio Gracia. Boletín Informativo del Excelentísimo Colegio Oficial de Médicos de la Provincia de Cádiz, 3, 7-10.

- Orozco-Acuaviva, A. (1981b). La Gaceta de Higiene y Climatología (1880-81) de Benito Alcina (1853-1902). Boletín Informativo del Excelentísimo Colegio Oficial de Médicos de la Provincia de Cádiz, 4, 16-18.

- Orozco-Acuaviva, A. (1981c). La Crónica de Especialidades Médico-Quirúrgicas (1884-1886) de Cayetano del Toro y Benito Alcina. Boletín Informativo del Excelentísimo Colegio Oficial de Médicos de la Provincia de Cádiz, 7, 5-9.

- Orozco-Acuaviva, A. (1981d). Bibliografía MédicoCientífica Gaditana. Cádiz: Obra Cultural Casino Gaditano.

- Orozco-Acuaviva, A. (1983). La Prensa Médica Gaditana (1916) de Bartolomé Gómez Plana (18601928). Boletín Informativo del Excelentísimo Colegio Oficial de Médicos de la Provincia de Cádiz, 1, 16-21.

- Orozco-Acuaviva, A. (1987) Los «Los Archivos Homeopáticos» de Cádiz (1835). Anales de la Real Academia de Medicina y Cirugía de Cádiz, XXIII, 2, 3544.

- Puelles-Benítez, M. de (1980). Educación e ideología en 


\section{Cultura de los Cuidados}

la España contemporánea (1767-1975). Barcelona: Ed. Labor.

- Ramos-Contreras, A. (1994). Una institución romántica gaditana: La Real Academia de Medicina y Cirugía de Cádiz. Origen y evolución (1815-1900). Tesis doctoral (inédita). Facultad de Medicina. Universidad de Cádiz.

- Riera-Palmero, J. (1978). Introducción, edición e índices de J. Riera. En: Méndez Álvaro, F.: Historia del periodismo médico y farmacéutico en España (pp. 11-19 y pp. 171-179). Valladolid: Servicio de Publicaciones de la Universidad de Valladolid.

- Rubio y Galí, F. (1868). Apuntes de mi práctica sobre los tumores y quistes del ovario y el resultado de su tratamiento médico y quirúrgico. Sevilla: Imprenta y
Librería de José M. Geofrin.

- Rubio y Galí, F. (1977). Mis maestros y mi educación. Madrid: Tebas.

- Sánchez de la Cuesta, G. (1949). Ideario y grandeza de don Federico Rubio. Sevilla: Real Academia de Sevilla.

- Sebastianes-Marfil, M. del C. (1995). La anestesia general en Andalucía a través de su prensa médica (1847-1936). Tesis doctoral. Microfichas. Barcelona: Universidad de Cádiz.

- Soto-Villalba, Juan. (2015). Las enfermedades del riñón y vías urinarias a través de la prensa médica gaditana (18201936). Tesis doctoral (inédita). Facultad de Medicina. Cádiz. 